\title{
A FUZZY MULTI-OBJECTIVE MODEL AND APPLICATION FOR THE DISCRETE DYNAMIC TEMPORARY FACILITIES LOCATION PLANNING PROBLEM
}

\author{
Jiuping XU', b, Qiurui $\mathrm{LIU}^{\mathrm{b}}$, Xiao $\mathrm{LEI}^{\mathrm{c}}$ \\ ${ }^{a}$ State Key Laboratory of Hydraulics and Mountain River Engineering, Sichuan University, \\ Chengdu, 610064, P. R. China \\ ${ }^{b}$ Uncertainty Decision-Making Laboratory, Sichuan University, Chengdu, 610064, P. R. China \\ ${ }^{c}$ China Three Gorges Corporation, Chengdu, 610051, P. R. China
}

Received 19 Jan 2013; accepted 09 May 2013

\begin{abstract}
The location of temporary facilities on construction sites is essential to the enhancement of productivity and safety, but it is complex due to the unique issues associated with construction. To positively contribute to the dynamic construction site layout planning field, this paper proposes a new fuzzy multi-objective decision making model. The proposed hybrid optimization model utilizes fuzzy numbers and logic to represent the closeness relationship between temporary facilities. The two main phases presented represent a specific advance in knowledge in through: (1) an optimization model that considers both uncertainty and dynamic elements; (2) the application of this optimization to a special project. A multi-objective simulated annealing-based genetic algorithm (MOSA-based GA) is proposed to solve the model and the case of Jinping-II hydroelectric station is studied to evaluate the model's performance. The computational study was carried out to demonstrate the practicality and efficiency of the proposed optimization method. The study is applicable and useful to the profession.
\end{abstract}

Keywords: decision making model, dynamic facilities allocation, fuzzy, optimistic.

\section{Introduction}

Facility location planning management in large scale hydropower construction is difficult in China, and often suffers from a significant waste of the resources as the real environment is complex, uncertain, and of long duration and high cost (Gang, Xu 2010; Xu, Li 2012; Xu, Zhang 2012). The transportation conditions are given and the available land for temporary facilities is often limited and isolated. Further, the project duration is often divided into several stages with the location of the temporary facilities changing with each different stages. So the model considered here is a discrete problem (Domschke, Krispin 1997) and the dynamic problem (Ning et al. 2010; Rosenblatt 1986).

Previous construction site layout planning research has tended to concentrate on static problems (Yeh 1995; Cheung et al. 2002; Li, Love 1998). However, due to the constantly changing nature of construction sites, this static layout becomes obsolete after any significant progress in the project (Osman et al. 2003). Static layout planning models ignore the possible reuse of site space to accommodate different resources at different times, the relocation of resources, and the varying space needs of resources over time (Ning et al. 2010; El-Rayes, Said 2010). While models that deal with dynamic layout planning in construction have been limited (Elbeltagi, Hegazy 2004), there is an increasing number of studies focusing on solving dynamic construction site layout planning problems (Zouein, Tommelein 1999; Baykasoglu et al. 2006; Ning et al. 2010). They further developed a computationally decision-making system to solve the dynamic, multi-objective and unequal-area construction site layout planning problems (Ning, Wang 2011).

In addition, subjective uncertainty leads to inefficiency in layout planning problems (Emre et al. 2009). In practice, this uncertainty is caused by internal forces, such as the decision makers' perceptions and dissension. Current research in construction site layout planning problems deals with this subjective uncertainty using fuzziness (Ning, Wang 2011; Soltani, Fernando 2004; Mawdesley, Al-Jibouri 2003; Maravas, Pantouvakis 2012).

A further element to consider is that previous research mainly considers only a single objective function, e.g. Elbeltagi et al. (2001), Elbeltagi and Hegazy (2004), El-Rayes and Said (2010), while, in fact, a good layout

Corresponding author: Jiuping $\mathrm{Xu}$

E-mail:xujiuping@scu.edu.cn 
has a number of competing, and yet often conflicting design objectives (Xu, Li 2012). The complex nature of decision-making in construction design and management requires practitioners to make decisions based on a wider variety of policy considerations in addition to cost benefit analysis and pure technical considerations (Turskis et al. 2009).

However, each layout design application is unique in nature as there are different attributes associated with different applications (Yang, Hung 2007). So far, there have been few studies comprehensively considering multiple-objectives, and dynamic and fuzzy problems in construction site layout planning (Nicklow et al. 2010), and especially, in an application study on a large scale hydropower construction project. From a realistic aspect, construction site layout planning tends to be dynamic and uncertain in nature and needs to fulfill conflicting objectives. Therefore, this paper proposes a multi-objective dynamic construction site layout planning model under a fuzzy environment with a representative case study.

The model incorporates dynamic and uncertain features in its formulation. Here, the facility location planning problem is considered to be discrete and dynamic on a given transportation network, which we have called a Discrete Dynamic Temporary Facilities Location Planning Problem (DDTFLPP) (see Fig. 1). According to Mawdesley and Al-Jibouri (2003), this study is a beneficial exploration for research into site layout problems as it develops a more suitable model, by adding uncertainty and including dynamic layouts. Moreover, the presented methodology is relatively similar to what practitioners are using today, but is considerably more effective and realistic in modelling.

The paper presents a new hybrid optimization model for the problem of dynamic site layout planning. The proposed model utilizes fuzzy numbers and logic to represent the closeness relationship between temporary facilities. The following summary is the organization of our paper. In Section 1, we analyze the DDTFLPP model and deal with the fuzzy factors that influence the decision making process. In Section 2, we generate an optimal site location planning model for each stage. To improve the efficiency of complex design problems, a

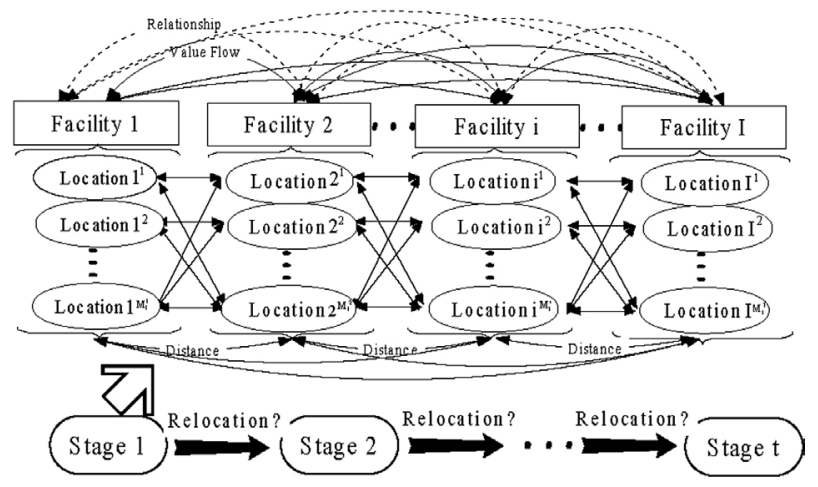

Fig. 1. The DDTFLPP multi-objectives simulated annealing based genetic algorithm (SA-based MOGA) is suggested. Then, we apply the DDTFLPP to a problem at the Jinping-II hydropower construction project and make some comparisons in Section 3. The conclusions to our paper are also presented.

\section{DDTFLPP statement}

Traditional management suffers from relocation waste, and the unnecessary movement and handling of materials. Tompkins et al. (1996) estimated that 20 50\% of costs are related to handling, so an optimum arrangement might reduce the handling cost by $10 \sim 30 \%$, thus assisting the economic management of a project.

The DDTFLPP handling cost is caused by the value streams, namely the material flows (MF), the information flows (IF), the personnel flows (PF), the equipment flows (EF) and the safety/environmental concerns (SE) (Karray et al. 2000; Dweiri, Meier 1996; Deb, Bhattacharyya 2005; Elbeltagi, Hegazy 2001). Because these flows are difficult to estimate, there is often inadequate data or imprecise information (Emre et al. 2009). Further, construction managers often perform decision making tasks using previous experience, which leads to ambiguity and inefficiency (Mawdesley, Al-Jibouri 2003; Maravas, Pantouvakis 2012). The value streams are vague and based on fuzzy theory (Xu, Zhou 2010; Zadeh 1965). To overcome this fuzziness, fuzzy measurement can be used to safeguard against vagueness.

Fuzzy factors are useful as it is, more convenient for managers to give a vagueness range for a decision than to give an exact digital. By using fuzzy theory $(\mathrm{Xu}$, Zhou 2010; Zadeh 1965), historical data, the subjective judgment of experts and the current available data can be combined. For instance, a decision maker often uses linguistic language such as "Medium" to describe the level of the value stream for the MF. He means the value stream is "between 3000 units and 6000 units, with the most likely value range $[3500,5000]$ '. In this case, we can use a trapezoidal fuzzy number (1600, 3000, 4500, 6000). Similarly, by interviewing different experienced engineers (i.e., $q=1,2, \ldots, E$, where $q$ is the index of engineers), we can establish all the membership functions for the value streams, i.e. $(l, a, b, m)$ ( $l$ is the left border, $r$ is the right border, $a$ and $b$ is the most likely value range). It should be noted that the $(l, a, b, m)$ is different for each decision maker because of different preference, experiences and scanty data. Generally, the view of each engineer can be denoted as a range, (i.e., $\left[l_{q}, r_{q}\right]$ ) and a most likely range of value (i.e., $\left[a_{q}, b_{q}\right]$ ). The minimal value of all $l_{q}$ and the maximal value of all $r_{q}$ is selected as the left border (i.e., $l$ ) and the right border (i.e., $r$ ), respectively. The minimal value of all $a_{q}$ is regarded as the left border of the mean range (i.e., $a$ ). The maximal value of all the $b_{q}$ (for $q=1,2, \ldots, E$ ) is regarded as the right border of the mean range (i.e., $b$ ).

The closeness relationship is a comprehensive selection routine to determine the location. In China, the nu- 


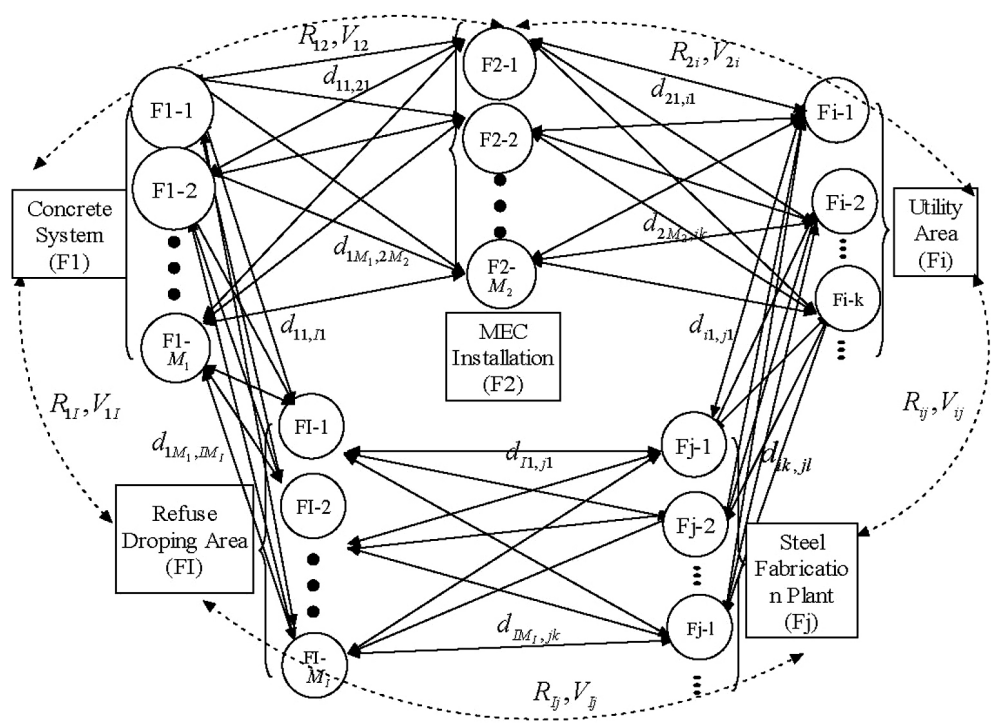

Fig. 2. The network of the DDTFLPP

merical ratings for the closeness relationship are usually arbitrarily assigned for the relationship chart. This is a typical extensive management type which seeks to imitate the decision makers' decision processes, but which in practical applications are not precise because the fuzzy decision system would need $5^{5}=3125$ rules when the closeness relationship is divided into five levels, i.e. " $\mathrm{A}$ ", "E", "I", "O", "U". Thus, here, we have attempted to make the closeness relationship defuzzification method simpler and easier.

In contrast with the traditional method, we sought another intuitive strategy. Each $\mu_{s}(v)$ is assumed to have a weight factor that affects the closeness relationship (Saaty 1980). We use this weight $w_{s}$ as the coincidence indicator, which can be obtained by the modification of the defuzzification methodology (Gentile et al. 2003):

$$
w_{s}=\frac{\frac{\int v \mu_{s}(v) d v}{\int \mu_{s} d v}}{\sum_{s=1}^{5} \frac{\int v \mu_{s}(v) d v}{\mu_{s} d v}}, \sum_{s=1}^{5} w_{s}=1,
$$

where $s=1,2, \ldots, 5$ indicates MF, IF, PF, EF and SE respectively, $v$ is the cost value between each pair of facilities per day. Then, the function of the closeness relationship can be stated as:

$$
\mu(r)=\sum_{s=1}^{5} w_{s} \mu_{s}(v)
$$

where $r$ is the total score of the closeness relationship. We use Zétényi's (1988) method to calculate the crisp rating of closeness relationship:

$$
R=\frac{\int_{-\infty}^{+\infty} \mu(r) r d r}{\int_{-\infty}^{+\infty} \mu(r) d r},
$$

where $R$ is the final crisp rating.
As shown in Figure 1, there are $I$ kinds of temporary facilities and $M_{i}$ possible locations for each facility $i$ in a stage $t(T$ is the number of stages, $t=1,2, \ldots, T)$. The decision makers need to assign facilities to the corresponding locations based on the requirements for the different stages. From the physical model shown in Figure 2, we can us $x_{i m k}(t)=\{0,1\}, i=1,2, \ldots, I$ to represent the decision variable. When $x_{i m k}=1$, this means the temporary facility $i$ moves from location $m$ to $k . d_{i k, j l}$ is the distance between location $k$ of facility $i$ and location $l$ of facility $j$. $v_{i j}$ is the cost value between facility $i$ and facility $j$.

\section{Modelling}

To obtain the above statement and gain further insight into the modelling of the DDTFLPP, preparation work was conducted. First, previous research was investigated to determine the relationship between the DDTFLPP parameters. Secondly, investigations and surveys were made with experienced managers to collect relevant information. Thirdly, we statistically analyzed the data using SPSS 19.0. From this information we derived the physical model in Figure 2 and from this the optimization model evolved.

\subsection{Assumption}

Based on the network shown in Figure 2, we have the following assumptions:

(1) We treat the locations of the facilities as dots, and neglect the areas and the orientation.

(2) On networks, the distances correspond to real road distances.

(3) The transportation cost is the main factor for the choice of locations. It was assumed to be proportional to the distances and intensity of the value flows. Transportation, resource and handling costs are assumed to be linear.

(4) We neglect the unpredictable impacts. 
(5) Planners specify the start of the stages to coincide with schedule milestones.

In order to make it easier to read, a precise explanation of the symbols used in the description of the mathematical model are introduced. According to the problem statement mentioned above, the notations are as follows:

Sets and Subscripts

$\Phi$ : set of kinds of temporary facilities, $i, j \in \Phi$;

Y: set of possible locations of the temporary facilities, $l, k \in \mathrm{Y}$;

$\Omega$ : set of all kinds of temporary facilities, $m, n \in \Phi$;

$\Psi$ : set of all stages, $t \in \Psi$;

Parameters

$d_{i k, j l}$ : distance between location $k$ of facility $i$ and location $l$ of facility $j, i, j \in \Phi, l, k \in \mathrm{Y}$;

$v_{i j}(t)$ : cost value between facility $i$ and $j, i, j \in \Phi$, $t \in \Psi$

$a_{i m}$ : variable cost when facility $i$ is built in location $m, i \in \Phi, m \in \Phi$

$c_{i}$ : fixed cost when facility $i$ is located, $i \in \Phi$;

Functions

$F(t)$ : total value of interaction flow in period $t, t \in \Psi$; $C^{*}(t)$ : the minimum cost for all periods up to $t, t \in \Psi$; Decision Variables

$$
x_{i m k}(t)=\left\{\begin{array}{l}
1, \text { move the temporary facility } i \text { from } \\
\text { location } m \text { to } k \\
0, \text { otherwise }
\end{array} .\right.
$$

\subsection{State equation}

The state equation can explain the effect between the different stages (Haidar 2009). This effect is reflects in many aspects, such as the cost, safety, the environment, and operations management. Combining Rosenblatt's (1986) model with our DDTFLPP, a recursive formulation is developed as the total cost from the initial stage to the $t^{\text {th }}$ stage. We establish the state equation in the following form:

$$
\begin{aligned}
& C^{*}(t)=\min \left\{C^{*}(t-1)+\sum_{i=1}^{I} \sum_{m=1}^{M} \sum_{k=1}^{M}\left(a_{i m}+c_{i}\right) x_{i m k}(t)\right\}+ \\
& F(t), \forall t \in \Psi,
\end{aligned}
$$

where $a_{i m}$ is the variable cost when facility $i$ is builded in location $m . c_{i}$ is the fixed cost.

The rearrangement cost is zero, if no change is made from one period to another. $F(t)$ can be made a function of the period of the total interaction flow value. $F(t)$ is obtained as in Section 2.5. $C^{*}(t)$ is the minimum cost corresponding with the DDTFLPP for all periods up to $t$.

\subsection{Initial and terminal conditions}

The key to finding the optimum solution for all phases lies in identifying which phase to consider as the initial phase. Dynamic optimization should then proceed in forward chronological order for succeeding phases and backward chronological order for preceding phases.
At the beginning, i.e. $t=1$, none of the facilities have been previously allocated to any of the locations. Thus, the decision valuable and the initial condition can be stated as:

$$
x_{i m k}(1)=0, C^{*}(1)=C_{1}, \forall i \in \Phi, m \in \Omega, k \in \mathrm{Y},
$$

where $C_{0}$ denotes the initial cost at the beginning of the whole period. Similarly, at the end of the whole construction duration, i.e. $t=T$, the final condition can be stated as:

$$
C^{*}(T)=C_{e} \text {. }
$$

$C_{e}$ is the cost value designed by the construction designer at the last stage.

\subsection{Constraint conditions}

As the facilities are treated as discrete dots, we only consider the department location restrictions (Meller, Gau 1996). If $m=k$ in $x_{i m k}$, the facility doesn't move. The following constraints guarantee one facility is assigned to one location and one location can accommodate no more than one facility because of the environmental conditions:

$$
\left\{\begin{array}{l}
\sum_{m=1}^{M} \sum_{k=1}^{M} x_{i m k}(t)=1, \quad \forall i \in \Phi, t \in \Psi, \\
\sum_{n=1 l=1}^{M} \sum_{j n l}^{M} x_{j l}(t)=1, \quad \forall j \in \Phi, t \in \Psi, \\
\sum_{i=1}^{I} x_{i m k}(t) \leq 1, \quad \forall m \in \Omega, t \in \Psi, \\
\sum_{j=1}^{I} x_{j n l}(t) \leq 1, \quad \forall n \in \Omega, t \in \Psi .
\end{array}\right.
$$

\subsection{Objective functions}

The first objective function $f_{1}$ is to minimize the total site location cost and handling cost between the facilities. The cost for each single facility is composed of two parts, the fixed cost and the variable cost.

It is not enough to just minimize the cost for each single facility as there are MF, IF, PF, and EF operating between the different facilities, so an optimum dynamic site layout plan seeks to minimize this interaction.

In phase $t$, if facility $x$ is located in location $i$, facility $y$ is located in location $j$ and there are interaction activities between $x$ and $y$. Based on the handing cost function (Aiello et al. 2006) and the redinteraction flow value from Ning's et al. (2010) research, the function for the DDTFLPP interaction flow in DDTFLPP is defined as:

$$
\begin{gathered}
\mathrm{F}(t)=\sum_{i=1}^{I} \sum_{j=1}^{I} \sum_{m=1}^{M} \sum_{k=1}^{M} \sum_{n=1}^{M} \sum_{l=1}^{M} v_{i j}(t) d_{i k, j l}, \\
x_{i m k}(t) x_{j n l}(t), \forall t \in \Psi,
\end{gathered}
$$

where $v_{i j}(t)$ is the cost value between facility $i$ and facility $j$ at stage $t$. 
Frequently, based on Eqns (4) and (8), the total cost during the entire DDTFLPP can be obtained as:

$$
\begin{aligned}
& \min f_{1}=C^{*}(T)= \\
& \min \left\{C^{*}(T-1)+\sum_{i=1}^{I} \sum_{m=1}^{M} \sum_{k=1}^{M}\left(a_{i m}+c_{i}\right),\right. \\
& \left.x_{i m k}(T-1)\right\}+F(T) .
\end{aligned}
$$

In the construction industry the risk of a fatality is five times more than that in a manufacturing based industry, and the risk of a major injury is two and a half times higher (Gangolells et al. 2010). Safety and environmental issues are therefore extremely important when designing construction site layout. A well-planned and well-run project should be both safe and efficient to save lives and money, and reduce injury and ill-health. From previous studies it is known that the nearer two kinds of facilities are, the greater the chance of serious accidents. Thus, for safety is necessary to find a balance between the distance and the closeness relationship. A distance-weighted flow is often used to measure the cost term of the closeness relationship (Fortenberry, Cox 1985). But such an approach has poor practicability due to the difficulty of normalizing the variables and quantifying the weights (Aiello et al. 2006). So, here, we modify the measurement into the second objective $f_{2}$ to minimize the closeness relationship effect:

$$
\min f_{2}=\sum_{t=1}^{T} \sum_{i=1}^{I} \sum_{j=1}^{I} \sum_{m=1}^{M} \sum_{k=1}^{M} \sum_{n=1}^{M} \sum_{l=1}^{M} R_{i j} d_{i k, j l} x_{i m k}(t) x_{j n l}(t),
$$

where $R_{i j}$ is calculated using Eqn (3). The intention is to assign higher values to more critical temporary facilities between which heavy material handling traffic will occur, thus there are more productivity or safety gains from placing them closer together.

In this way, the two objectives numerically assess the efficiency of the layout sequence by minimizing the cost and maximizing safety. These objectives are complementary rather than contradictory and guarantee that the project is carried out successfully and efficiently, with maximum advantage taken of all the facility resources. Consequently, both economic and resource aspects considered.

To ensure a comprehensive understanding of the optimization in the DDTFLPP, the state equation (see Eqn (4)), initial and terminal conditions (see Eqns (5) and (6)), constraint conditions (see Eqn (7)) and objective functions (see Eqns (8), (9) and (10)) have been presented subsequently in the above statement. From this, we can then formulate the mathematical optimization model for the multiple objective multistage DDTFLPP under a fuzzy environment. Therefore, the DDTFLPP model can be proposed as:

$$
\begin{aligned}
& \min f_{1}=C^{*}(T) \\
& \min f_{2}=\sum_{t=1}^{T} \sum_{i=1}^{I} \sum_{j=1}^{I} \sum_{m=1}^{M} \sum_{k=1}^{M} \sum_{n=1}^{M} \sum_{l=1}^{M} R_{i j} d_{i k, j l} x_{i m k}(t) x_{j n l}(t)
\end{aligned}
$$

$$
\text { s.t. }\left\{\begin{array}{l}
C^{*}(t)=\min \left\{C^{*}(t-1)+\sum_{i=1}^{I} \sum_{m=1}^{M} \sum_{k=1}^{M}\left(a_{i m}+c_{i}\right),\right. \\
\left.x_{i m k}(t)\right\}+F(t) ; \\
F(t)=\sum_{i=1}^{I} \sum_{j=1}^{I} \sum_{m=1}^{M} \sum_{k=1}^{M} \sum_{n=1}^{M} \sum_{l=1}^{M} v_{i j}(t) d_{i k, j l} x_{i m k}(t), \\
x_{j n l}(t), C^{*}(1)=C_{1}, C^{*}(1)=C_{1} ; \\
x_{i m k}(1)=0, \forall i \in \Phi, m \in \Omega ; k \in \mathrm{Y} ; \\
\sum_{m=1}^{M} \sum_{k=1}^{M} x_{i m k}(t)=1, \forall i \in \Phi, t \in \Psi ; \\
\sum_{n=1}^{M} \sum^{M} x_{j n l}(t)=1, \forall j \in \Phi, t \in \Psi ; \\
\sum_{i=1}^{I} x_{i m k}(t) \leq 1, \forall m \in \Omega, t \in \Psi, k \in \mathrm{Y} ; \\
\sum_{j=1}^{I} x_{j n l}(t) \leq 1, n \in \Omega, t \in \Psi, l \in \mathrm{Y},
\end{array}\right.
$$

where $x_{i m k}(t), x_{j n l}(t) \in\{0,1\}, \Phi=\{1,2, \cdots, I\}$, $\mathrm{Y}=\{1,2, \ldots K\}, \Omega=\{1,2, \cdots, M\}$ and $\Psi=\{1, \cdots, T\}$. As we have introduced, $d_{i k, j l}$ is the distance between location $k$ of facility $i$ and location $l$ of facility $j . v_{i j}(t)$ is the cost value between facility $i$ and $j . F(t)$ is the function of the total value of the interaction flow. $C^{*}(t)$ is the minimum cost corresponding with the DDTFLPP for all periods up to $t$.

The model establishes the feasibility of an individual layout by satisfying the requirements of all resources while ensuring that all hard constraints between them are met.

\subsection{SA-based MOGA algorithm}

For the solution methods, a new hybrid SA-based MOGA is first integrated to optimize the DDTFLPP model in our paper. The hybrid SA-based MOGA adopts the basic exponential acceptance probability of simulated annealing (SA) as the criterion for testing and acceptance or rejection. The following 3 parts are inspirational and different from the pre-existing SA-GA hybrid algorithm.

Firstly, the proposed SA-based MOGA adopts the characteristics of chromosome which is the divided by level. As Figure 3 shows, each chromosome can be divided into four levels. First, the chromosome is divided by stage, with $T$ stages. Based on the first level, the second level is divided by the type of the facilities, with $I$ parts. The third level is divided by the candidate locations for each facility, with $M$ parts. The genes are put in order according to the index of facilities candidate locations. Thus, there are also $M$ genes in each subpart of the last level. Totally, there are $I \times M \times M \times T$ genes in one chromosome. Each chromosome $C_{n}$ represents a sequence of genes $x_{i m k}(t)$ for the DDTFLPP model, as in Figure 3. As the variables in our DDTFLPP are 0 and 1 , they are suited for the gene sections of the GA, and we omit the encoding and decoding procedure. In this 


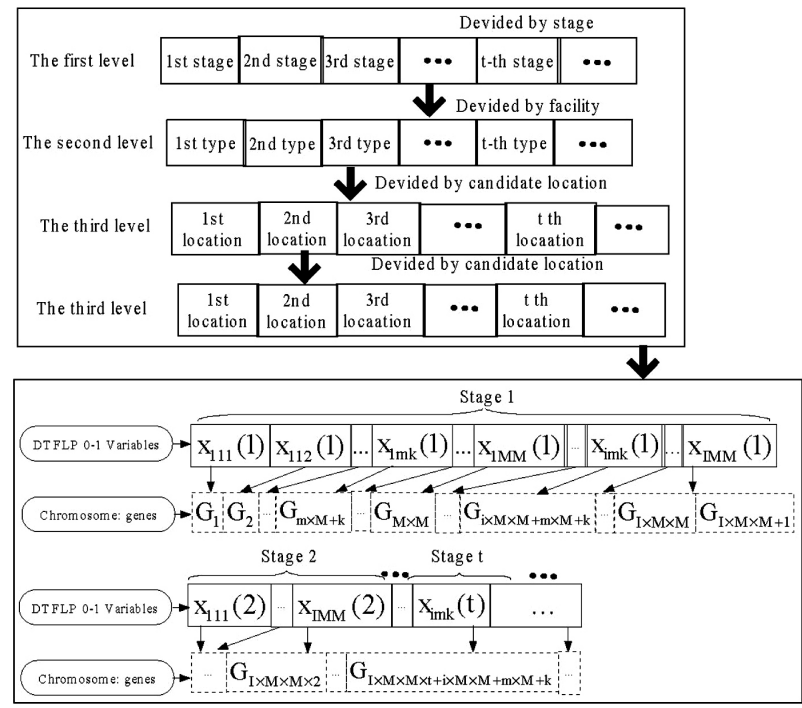

Fig. 3. Representation of the DDTFLPP in SA-based MOGA algorithm

way, we build the parallel structure for the chromosome representation in the SA-based MOGA algorithm. This kind of parallel structure can reduce the dimensionality of the solution thereby reducing the difficulty computing complexity. It should be noted that when initializing the first generation of the chromosome randomly, we can make sure that the solution is feasible by combining the constraints with each chromosome level separately, as shown in Figure 3. This also saves time in searching for the route and in the computation.

Secondly, there has not been any research that has adopted the concept of a fitness ranking matrix (Goldberg 1989) using the SA-GA hybrid algorithm to solve a multi-objectives problem. To reduce the difficulty of measuring the different objectives and avoiding subjective predilection to obtain the weights, we adopt the $F$ fitness ranking matrix (Goldberg 1989) to deal with the multiobjectives in the SA-based GA algorithm. This kind of aggregation allows for alternative schemes, which proves to be more effective as it cannot be dominated by one decision maker. The proposed hybrid SA-based MOGA exhibits a better convergence speed but is not always stable. However, compared to the weight-sum method, the solutions in this study are more practical.

Further, to make it more suitable for the DDTFLPP and to avoid an unfeasible solution, the proposed algorithm checks the solution three times: at initialization, in the neighborhood of the SA and when the new population of the GA is determined after the crossover and mutation, as shown in Figure 4.

The SA-based MOGA algorithm procedure is shown in Figure 4. In Figure 4, we used the SA parameters $\rho$ (Bennage, Dhingra 1995) and $T$ (Kirkpatrick et al. 1983). For the GA parameters, we used the uniform crossover technique (Back et al. 2000) and the jump mutation to break the stagnation in improvement (Nicklow et al. 2010). Additionally, to try to find a suitable algorithm re-

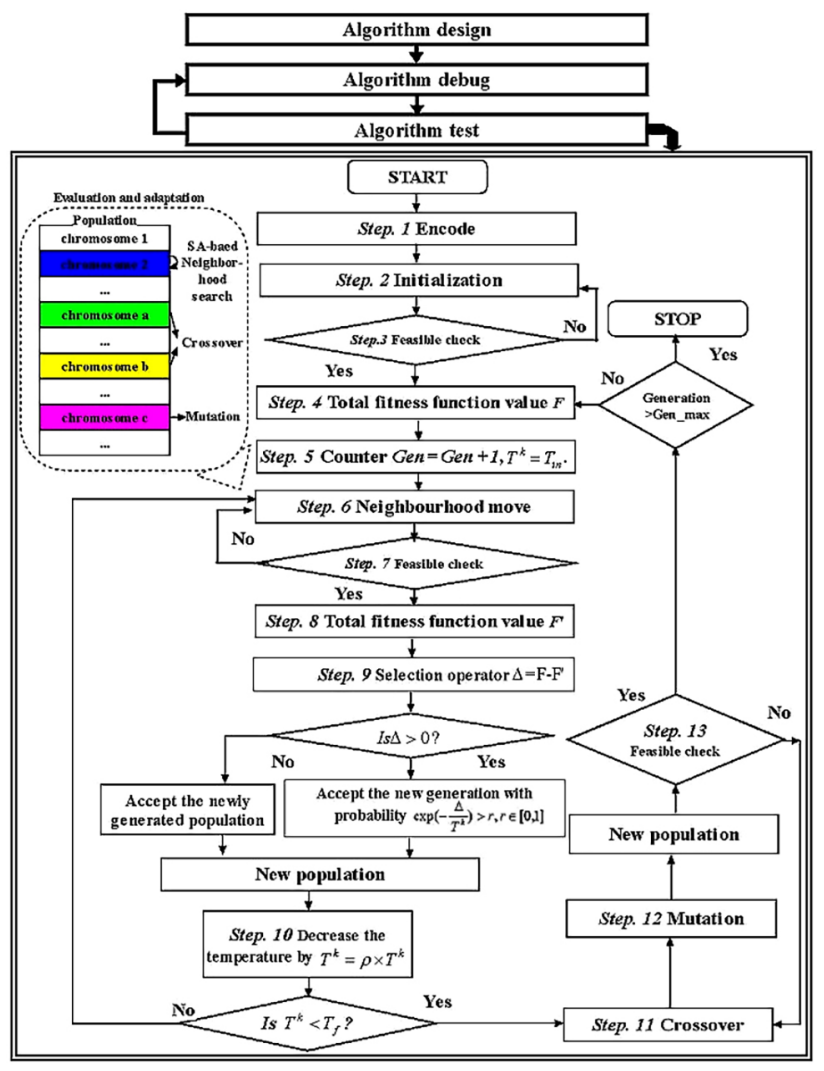

Fig. 4. The SA-based MOGA algorithm proceeding

quired a kind of advanced computer language or database management software to write program and on machine debugged basic technical ability. It should be noticed that the pre-existing GA package provided by the Matlab was not used as it is only able to solve some simple problems and cannot be combined with the SA. Therefore, the proposed algorithm was implemented on a new program in Matlab 7.0 and on a Pentium 4, 2.40 GHz 17 clock pulse with 1024 MB memory. The actual case study project was conducted on the system to test its wide applicability and to demonstrate the system capabilities.

\section{Practical application}

As for the further implementation of the decision making model, it requires three parts of preparation work. The first part is that the manager needs to systemize the closeness relationship and the geographical relation of the facilities in the DDTFLPP corresponding to practical case from the model formulation. The second part is to collect the information of the certain variables in the decision making model. These two parts could be done by the help of using the Engineering Sciences Data Unit, consulting the Certified Energy Manager program and communicating with the local project contractor. The third precondition is to do some computer technology work in the algorithm debugging and algorithm test which is to adjust the suitable algorithm parameters to the specific practical case. It requires the participation of the actual operation manager whose experience in the measurement 
of the results was very important. The specific preparation time is various with the scale of the actual project. Generally, this systematization work costs about one or two days. The second part spends about 2 to 3 days and the last part needs about 1 day. For the following case study, the setup time spent us a total of 5 days.

An actual DDTFLPP construction project was studied as a practical application for the proposed optimization method. The "Jingping Bend"" is the main stream of the Yalong River, in southwest of China $28.12833^{\circ} \mathrm{N}$ $101.79083^{\circ} \mathrm{E}$, as shown in Figure 5. The length of the "Jingping Bend" is $150 \mathrm{~km}$ but downstream the opposite side is only separated by $16 \mathrm{~km}$. Between that distance, there is an elevation drop of $310 \mathrm{~m}$, creating an excellent situation for hydroelectric production. Two projects are planned for the bend, the Jinping I and Jinping II hydropower stations with a combined capacity of 8,400 MW. Located at $28^{\circ} 07^{\prime} 42^{\prime \prime} \mathrm{N} 101^{\circ} 47^{\prime} 27^{\prime}$ E, the Jinping-II Hydropower Station is the largest-scale constructions for the West-East Electric Transmission Project of China and has the largest hydraulic tunnel in the world. The hydropower construction total installed power is 4.8 million KW. The generated energy is 242.3 billion $\mathrm{kw} \cdot \mathrm{h}$ a year. Once completed, it will have a powerful regulating ability with a normal pool level of $1646 \mathrm{~m}$ and reservoir capacity of 14.01 million $\mathrm{m}^{3}$. The construction project began in July 2007 and the total duration of the construction is expected to be 8 years and 3 months.

The main permanent structures of the Jinping-II project are the Maomaotan Sluice Dam, the diversion system and the power house. The Maomaotan Sluice Dam on the west-side of the Jinping bend will divert water into a $16.6 \mathrm{~km}$ long headrace tunnel towards the Jinging-II Power Station. From the left sub-figure in Figure 5 we can see the Maomaotan Sluice Dam and the power house are separated by mountains. There is no real road between them except for the Jinping Highway along the Jinping Bend. There are 10 principal areas of the Jinping-II large-scale water conservancy and hydropower construction project. They are the Songlinping Area, the Dabenliu Stockpile Area, the Maomao Bank Sluice Dam, the Yinbazigou Area, the Jingfeng Bridge Stockpile Area, the Daping Area, the Santan Droping Area, the Muofanggou Area, the Zhoujiaping Area and the Muosagou Area. The Songlinping Area is the work area and excavation treatment area on the slope of the west bank. The Dabenliu Stockpile Area and the Jingfeng Bridge Stockpile Area are the reservoir areas in the western area. The Maomao Bank Sluice Dam is the retaining dam. The Yinbazigou Area is the concrete pouring system for the west bank diversion and the diversion tunnel area. The Daping Area is the river closure, cofferdam and excavation treatment areas for the river bed. The Santan Dropping Area is spoil dumping site for the west work areas. The Muofanggou Area is a navigation structure excavation treatment with a steel tube fabrication plant in the eastern areas. The Zhoujiaping Area is a concrete pouring system in the eastern area, as well as being used for servicing the plant construction the installation of the metal structures for the generating system and the electrical installation. The Muosagou Area is used for the water diversion, the tailrace system in the underground powerhouse, the flood system and the ship lift system. When we enlarge the left sub-figure of Figure 5 to 5 times, we can see the detailed candidate locations which are chosen because of they are along the Yalong River and the traffic lines. In the top left corner of Figure 5 is the blueprint for the Jinping-II station. The middle-upper area of Figure 5 shows concrete pouring site for the Jinping-II station. The entrance to the diversion tunnel on the west bank can be seen in the top right hand corner of Figure 5.

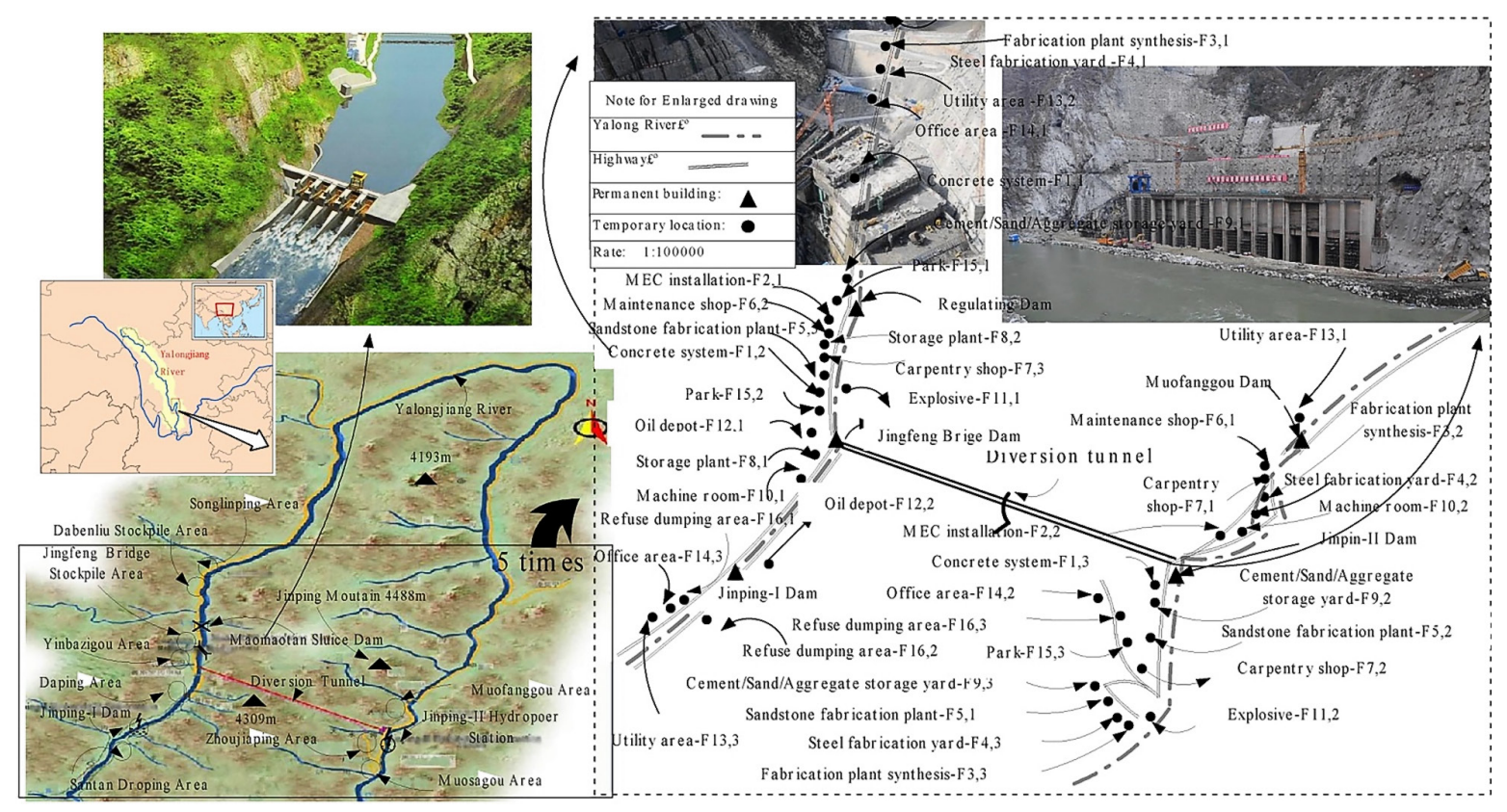

Fig. 5. The map of Jinping II hydropower construction 
By investigating the natural environment and the location of the main structures, our work is to provide a proper alternative construction location planning which includes the warehouse, the affiliated companies, the stationary facilities and other areas.

\subsection{Data collection}

Table 1 . The list of temporary facilities and the corresponding variables

\begin{tabular}{llccccc}
\hline No. & Facility & $\begin{array}{c}\text { Loca- } \\
\text { tions }\end{array}$ & $\begin{array}{c}\text { Fixed } \\
\text { cost }\end{array}$ & \multicolumn{3}{c}{$\begin{array}{c}\text { Variable cost } \\
\text { (in RMB) }\end{array}$} \\
\hline F1 & $\begin{array}{l}\text { Concrete } \\
\text { system }\end{array}$ & 3 & 77.9546 & 11.74 & 15.63 & 43.89 \\
\hline F2 & $\begin{array}{l}\text { MEC } \\
\text { installation }\end{array}$ & 2 & 129.91 & 19.56 & 27.24 & 1000 \\
\hline F3 & $\begin{array}{l}\text { Fabrication } \\
\text { plant synthesis }\end{array}$ & 3 & 3.6 & 0.78 & 1.16 & 0.53 \\
\hline F4 & $\begin{array}{l}\text { Steel } \\
\text { fabrication } \\
\text { yard }\end{array}$ & 3 & 1.775 & 1.12 & 0.89 & 1.34 \\
\hline F5 & $\begin{array}{l}\text { Sandstone } \\
\text { fabrication } \\
\text { plant }\end{array}$ & 3 & 39.74 & 4.76 & 10.33 & 6.36 \\
\hline F6 & $\begin{array}{l}\text { Maintenance } \\
\text { shop }\end{array}$ & 2 & 2.43 & 0.32 & 0.73 & 1000 \\
\hline F7 & $\begin{array}{l}\text { Carpentry } \\
\text { shop }\end{array}$ & 3 & 1.449 & 0.19 & 0.89 & 0.16 \\
\hline F8 & Storage plant & 2 & 3.26 & 0.28 & 1.89 & 1000 \\
\hline F9 & $\begin{array}{l}\text { Cement/Sand/ } \\
\text { Aggregate } \\
\text { storage yard }\end{array}$ & 3 & 4.38 & 0.57 & 0.26 & 1.03 \\
\hline F10 & Machine room & 2 & 5.67 & 0.65 & 1.47 & 1000 \\
\hline F11 & $\begin{array}{l}\text { Explosive } \\
\text { depot }\end{array}$ & 2 & 1.674 & 0.12 & 0.54 & 1000 \\
\hline F12 & $\begin{array}{l}\text { Oil depot } \\
\text { F13 }\end{array}$ & 2 & 1.93 & 0.65 & 0.28 & 1000 \\
\hline F14 & Otility area & 3 & 162.36 & 34.69 & 13.31 & 15.52 \\
\hline F15 & Parking lot & 3 & 7.8 & 1.74 & 0.68 & 1.15 \\
\hline F16 & $\begin{array}{l}\text { Refuse } \\
\text { dumping area }\end{array}$ & 3 & 11.18 & 1.36 & 1.52 & 3.13 \\
\hline & 3 & 59.36 & 6.88 & 9.56 & 10.45 \\
\hline
\end{tabular}

For the current study, the data was obtained from three sources: the database of the Sanxia Lt. Company, observation of the Jinping-II Power Station managerial practice and interviews with relevant managers and personnel. As a further note, the investigation of the closeness relationship between the facilities in the project management practice can ascertain the validity of the measurement techniques proposed in Section 1. Interviews were conducted face to face with construction managers to provide an opportunity for us to improve data precision. The construction managers' project experience can assists in the comprehension of the specific nature of the facilities. In this way, the data is gathered for each the resource dimensions, weights, and constraints.
The closeness relationships and the value flows between the facilities are showed in Tables 2 and 3 respectively. The distances between the locations $d_{k l}$ are also known, as shown in Tables 4 and 5 .

As we have stated the enlarged drawing of the Jinping-II Hydropower Station in Figure 5 includes some possible construction zones and available location dots for the temporary facilities. We can see that the Jinping-II construction main sub-projects and the site of these sub -projects change over time. Thus, based on the plan for each construction section, the principal part of the Jinping-II hydropower construction project can be divided into 3 stages: excavation, concrete pouring and MEC installation. Further, there are 16 kinds of temporary facilities involved in the principal part of the Jinping-II hydropower construction project. These facilities as well as their corresponding constant variables are listed in Table 1. It should be noted that, as in the last stage, i.e., $t=$ 3 , some facilities do not need to relocate or are closed, so the $a_{i 3}$ of these facilities is set at a very high level. A gradual decline in resources can thus be modeled by introducing a sequence of dummies of very short duration.

Based on the project information obtained from the contractor, the research team independently generated a site layout plan. The site plan was then presented to the contractor and the consultant for verification and comments.

\subsection{Results' discussion}

Using the proposed method, the processing time to obtain the optimum or near-optimum site layout was about $1 \mathrm{~min}$ on a Pentium $900 \mathrm{Mhz}$ personal computer. The SA-based GA parameters were set from the results of the

Table 2. The closeness relationship between facilities

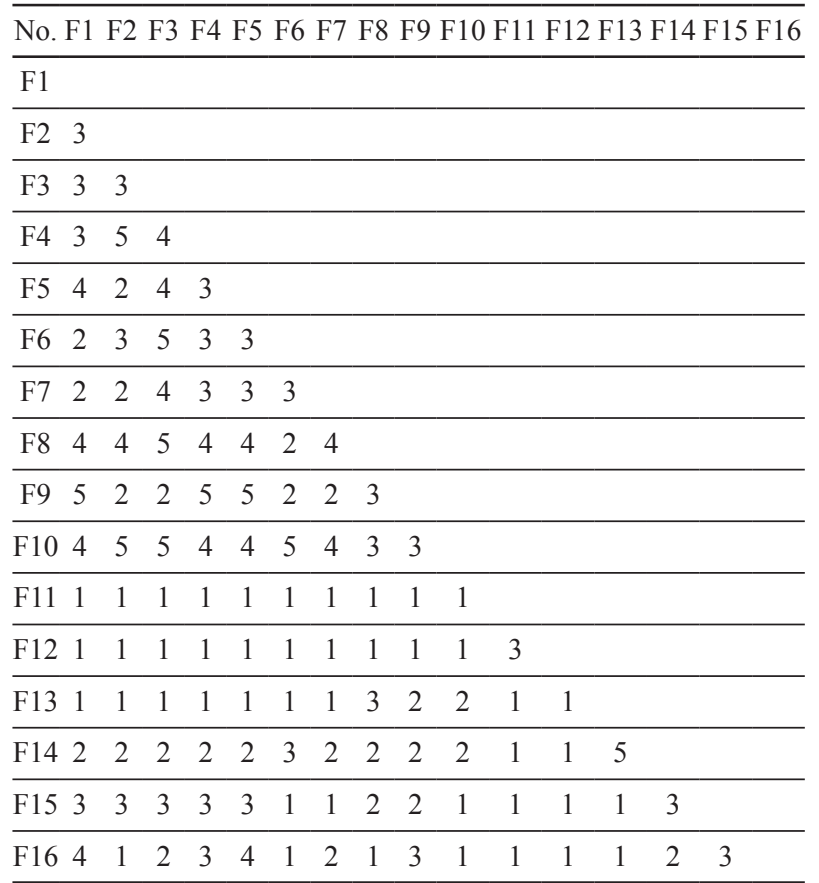


Table 3. The value flow $v_{i j}(t)$ between facilities (in 10 thousand RMB)

\begin{tabular}{|c|c|c|c|c|c|c|c|c|c|c|c|c|c|c|c|}
\hline No. & F1 & $\mathrm{F} 2$ & F3 & $\mathrm{F} 4$ & F5 & F6 & F7 & F8 & F9 & F10 & F11 & 12 & F13 & F14 & F15 \\
\hline & \multicolumn{15}{|c|}{ Stage $t=1$} \\
\hline F1 & - & & & & & & & & & & & & & & \\
\hline $\mathrm{F} 2$ & 14.67 & - & & & & & & & & & & & & & \\
\hline F3 & 1.36 & 98.94 & - & & & & & & & & & & & & \\
\hline $\mathrm{F} 4$ & 1.9 & 297.73 & 947.96 & - & & & & & & & & & & & \\
\hline F5 & 6.09 & 0 & 711.76 & 0.8 & - & & & & & & & & & & \\
\hline F6 & 0.4 & 0.28 & 0.46 & 0.29 & 0.62 & - & & & & & & & & & \\
\hline F7 & 1.16 & 1.46 & 1.47 & 0.96 & 0 & 0.08 & - & & & & & & & & \\
\hline $\mathrm{F} 8$ & 6.68 & 0.35 & 8626.78 & 1002.95 & 232.89 & 0.35 & 2.81 & - & & & & & & & \\
\hline F9 & 1194.56 & 0 & 7605.75 & 3.24 & 8854.07 & 0 & 0.49 & 0 & - & & & & & & \\
\hline F10 & 7.8 & 6.21 & 6.21 & 3.58 & 3.75 & 6.21 & 0.41 & 8.17 & 280.73 & - & & & & & \\
\hline F11 & 0 & 0.1 & 0.26 & 0.01 & 0 & 0 & 0 & 0 & 0 & 0 & - & & & & \\
\hline F12 & 6.6 & 0.16 & 0.95 & 1.77 & 1.69 & 0.06 & 0.08 & 0 & 0 & 5.96 & 0 & - & & & \\
\hline F13 & 1.76 & 264.62 & 87.57 & 36.04 & 7.56 & 0.85 & 0.87 & 0.54 & 104.43 & 74.67 & 36.56 & 0.52 & - & & \\
\hline F14 & 2.64 & 19.85 & 32.34 & 24.32 & 5.15 & 0.57 & 0.69 & 0.38 & 88.68 & 49.78 & 28.69 & 0.34 & 538.93 & - & \\
\hline F15 & 49.6 & 6.7 & 454.49 & 1128.9 & 10456.26 & 3.41 & 4.17 & 236.59 & 13.6 & 49.72 & 0.31 & 6.67 & 557.08 & 371.39 & - \\
\hline \multirow[t]{2}{*}{ F16 } & 26.32 & 4.93 & 14.54 & 86.34 & 290.75 & 0.04 & 0.07 & 0 & 1.96 & 0 & 0.01 & 0 & 0 & 17.61 & 45.79 \\
\hline & \multicolumn{15}{|c|}{ Stage $t=2$} \\
\hline F1 & - & & & & & & & & & & & & & & \\
\hline $\mathrm{F} 2$ & 142.23 & - & & & & & & & & & & & & & \\
\hline F3 & 12.13 & 1.46 & - & & & & & & & & & & & & \\
\hline $\mathrm{F} 4$ & 16.78 & 1741.37 & 543.57 & - & & & & & & & & & & & \\
\hline F5 & 2643.79 & 0 & 417.56 & 0.67 & - & & & & & & & & & & \\
\hline F6 & 113.21 & 75.84 & 24.24 & 16.53 & 25.42 & - & & & & & & & & & \\
\hline F7 & 711.34 & 8.54 & 33.81 & 35.52 & 1.87 & 1.32 & - & & & & & & & & \\
\hline F8 & 1.36 & 1198.34 & 10675.29 & 1741.29 & 10014.27 & 122.15 & 107.15 & - & & & & & & & \\
\hline F9 & 3381.11 & 0.02 & 35.39 & 74.52 & 377626.89 & 0 & 18.13 & 0 & - & & & & & & \\
\hline F10 & 893.52 & 212.9 & 1460.98 & 118.47 & 576.78 & 260.82 & 16.54 & 13.06 & 864.19 & - & & & & & \\
\hline F11 & 0 & 0.18 & 0.26 & 0.34 & 0 & 0 & 0 & 0 & 0 & 0 & - & & & & \\
\hline F12 & 5.03 & 0.94 & 32.91 & 69.03 & 78.39 & 2.76 & 3.36 & 0 & 0 & 781.62 & 0 & - & & & \\
\hline F13 & 274.72 & 36.26 & 2152.53 & 400.35 & 209.96 & 17.43 & 39.15 & 5.67 & 115.95 & 475.96 & 72.47 & 18.72 & - & & \\
\hline F14 & 100.03 & 34.29 & 1891.51 & 280.14 & 139.48 & 1.22 & 14.94 & 3.76 & 28.96 & 266.54 & 61.65 & 11.23 & 1297.26 & - & \\
\hline F15 & 1163.92 & 1747.52 & 2752.89 & 2090.46 & 378628.16 & 4.32 & 140.31 & 25.23 & 1163.78 & 341.31 & 14.26 & 264.66 & 487.93 & 29.36 & - \\
\hline \multirow[t]{2}{*}{ F16 } & 372.76 & 45.44 & 1541.56 & 64.74 & 12094.41 & 6.86 & 8.57 & 61.75 & 11263.38 & 0 & 0.02 & 0 & 1979.63 & 322.58 & 1959.76 \\
\hline & \multicolumn{15}{|c|}{ Stage $t=3$} \\
\hline F1 & - & & & & & & & & & & & & & & \\
\hline F2 & 96.71 & - & & & & & & & & & & & & & \\
\hline F3 & 7.3 & 1.22 & - & & & & & & & & & & & & \\
\hline $\mathrm{F} 4$ & 11.45 & 1253.53 & 91.82 & - & & & & & & & & & & & \\
\hline F5 & 1770.81 & 0 & 284.74 & 0.26 & - & & & & & & & & & & \\
\hline F6 & 184.13 & 131.44 & 60.26 & 15.92 & 11.21 & - & & & & & & & & & \\
\hline F7 & 7.88 & 5.38 & 19.94 & 30.76 & 0.16 & 0.12 & - & & & & & & & & \\
\hline F8 & 170.08 & 1924.42 & 225.19 & 1212.37 & 40.73 & 68.57 & 46.77 & - & & & & & & & \\
\hline F9 & 3993.48 & 0.01 & 195.37 & 1497.54 & 1536.23 & 0 & 12.89 & 0 & - & & & & & & \\
\hline F10 & 842.74 & 244.65 & 198.89 & 149.04 & 53.34 & 63.44 & 18.25 & 8.71 & 562.25 & - & & & & & \\
\hline F11 & 0 & 0.17 & 0.24 & 0.32 & 0 & 0 & 0 & 0 & 0 & 0 & - & & & & \\
\hline F12 & 3.34 & 1.15 & 11.43 & 44.85 & 72.12 & 3.12 & 0.73 & 0 & 0 & 197.78 & 0 & - & & & \\
\hline F13 & 147.23 & 185.48 & 1048.87 & 521.34 & 8.98 & 17.97 & 16.84 & 2.56 & 94.42 & 31.73 & 71.58 & 13.48 & - & & \\
\hline F14 & 77.57 & 96.43 & 125.69 & 187.67 & 2.16 & 4.67 & 3.54 & 0.77 & 15.23 & 17.76 & 59.43 & 3.13 & 64.89 & - & \\
\hline F15 & 370.52 & 472.65 & 552.43 & 1385.56 & 1577.39 & 2.93 & 84.85 & 22.09 & 1261.25 & 573.54 & 4589.46 & 19.63 & 609.91 & 280.32 & - \\
\hline F16 & 443.4 & 12.71 & 16.16 & 87.76 & 57.77 & 3.84 & 8.74 & 66.84 & 260.47 & 0 & 0.23 & 0 & 109.38 & 22.86 & 472.22 \\
\hline
\end{tabular}


Table 4. The distance $d_{i k, j l}$ between different possible locations of the facilities (a)

\begin{tabular}{|c|c|c|c|c|c|c|c|c|c|c|c|c|c|c|c|c|c|}
\hline \multirow[t]{2}{*}{ No. } & \multirow[b]{2}{*}{$m$} & \multicolumn{3}{|c|}{$\mathrm{F} 1$} & \multicolumn{2}{|c|}{$\mathrm{F} 2$} & \multicolumn{3}{|c|}{ F3 } & \multicolumn{3}{|c|}{$\mathrm{F} 4$} & \multicolumn{3}{|c|}{ F5 } & \multicolumn{2}{|c|}{ F6 } \\
\hline & & 1 & 2 & 3 & 1 & 2 & 1 & 2 & 3 & 1 & 2 & 3 & 1 & 2 & 3 & 1 & 2 \\
\hline \multirow{2}{*}{$\mathrm{F} 2$} & 1 & 3.3 & 1.6 & 18.5 & & & & & & & & & & & & & \\
\hline & 2 & 20.3 & 19 & 1.8 & & & & & & & & & & & & & \\
\hline \multirow{3}{*}{ F3 } & 1 & 3.7 & 8.2 & 88.1 & 7 & 87.1 & & & & & & & & & & & \\
\hline & 2 & 88.7 & 93.2 & 3.3 & 92.2 & 1.4 & & & & & & & & & & & \\
\hline & 3 & 97.4 & 102 & & 100.3 & 6.8 & & & & & & & & & & & \\
\hline \multirow{3}{*}{$\mathrm{F} 4$} & 1 & 3 & 8 & 88.6 & 5.8 & 87.7 & 0.6 & 86.3 & 93.2 & & & & & & & & \\
\hline & 2 & 90.3 & 94.9 & 2.8 & 92.6 & 1 & 85.4 & 1.2 & 7.8 & & & & & & & & \\
\hline & 3 & 96.6 & 100.9 & 4.2 & 100.2 & 6.5 & 93.2 & 7.9 & 0.4 & & & & & & & & \\
\hline \multirow{3}{*}{ F5 } & 1 & 95 & 100.5 & 3.5 & 99.7 & 6.2 & 92.8 & 7.5 & 0.7 & 93.3 & 6.6 & 3.2 & & & & & \\
\hline & 2 & 92.4 & 97.8 & 1.2 & 96.9 & 3.1 & 90 & 4.9 & 3.8 & 90.5 & 3.8 & 0.9 & & & & & \\
\hline & 3 & 4 & 0.5 & 96.6 & 1.3 & 95.4 & 8.3 & 93.7 & 100.7 & 7.6 & 91.2 & 96.3 & & & & & \\
\hline \multirow{2}{*}{ F6 } & 1 & 87.5 & 92.9 & 3.2 & 91.4 & 2 & 83.9 & 0.8 & 8.9 & 84.5 & 1.2 & 8.6 & 8.2 & 4.4 & 92.5 & & \\
\hline & 2 & 3.8 & 0.6 & 95.9 & 0.6 & 94.6 & 7.5 & 93 & 100.4 & 7 & 90.4 & 100.1 & 99.7 & 97.1 & 0.2 & & \\
\hline \multirow{3}{*}{ F7 } & 1 & 90.1 & 94.9 & 3.5 & 91.6 & 1.7 & 84.2 & 0.4 & 8.6 & 84.8 & 0.9 & 8.3 & 7.9 & 2.3 & 94.5 & 0.3 & 92.2 \\
\hline & 2 & 26.5 & 93.4 & 2 & 97.7 & 3.8 & 90.8 & 5.5 & 2.7 & 90.8 & 4.6 & 2.4 & 2 & 0.8 & 93 & 6.2 & 98.3 \\
\hline & 3 & 4.2 & 0.9 & 96.4 & 0.9 & 95.1 & 7.8 & 93.3 & & 7.3 & 90.7 & & & 97.6 & 0.5 & 92.6 & 0.3 \\
\hline \multirow{2}{*}{ F8 } & 1 & 6.3 & 8 & 96 & 3 & 97.2 & 10.1 & 95.4 & 102.7 & 9.5 & 92.9 & 102.4 & 102 & 97.2 & 8.4 & 94.7 & 2.4 \\
\hline & 2 & 3.1 & 1.5 & 98.8 & 0.3 & 94.4 & 7.3 & 92.7 & 100.3 & 6.7 & 9.2 & 100 & 99.6 & 100 & 0.9 & 92 & 0.3 \\
\hline \multirow{3}{*}{ F9 } & 1 & 2.3 & 2.2 & 94.6 & 1 & 93.1 & 6 & 91.4 & 98.4 & 5.7 & 91.9 & 98.1 & 97.7 & 95.8 & 1.8 & 91.7 & 1.6 \\
\hline & 2 & 19.9 & 98.6 & 0.4 & 96.1 & 2.2 & 99.2 & 4 & 4.6 & 89.8 & 3 & 4.3 & 3.9 & 0.8 & 98.2 & 4.7 & 97.7 \\
\hline & 3 & 95.2 & 100.8 & 3.7 & 100.1 & 5.7 & 92.3 & 7 & 1.2 & 92.8 & 6.5 & 0.9 & 0.5 & 2.7 & 100.4 & 7.7 & 101.7 \\
\hline \multirow{2}{*}{ F10 } & 1 & 7 & 2 & 99.3 & 3.2 & 97.3 & 10.6 & 96.1 & 103 & 10.1 & 95.6 & 102.7 & 102.3 & 100.5 & 2.4 & 95.4 & 2.6 \\
\hline & 2 & 90.7 & 95.1 & 2.5 & 93.4 & 0.5 & 85.9 & 1.7 & 7.3 & 87 & 0.5 & 7 & 6.6 & 1.3 & 94.7 & 2.4 & 94 \\
\hline \multirow{2}{*}{ F11 } & 1 & 4.8 & 0.5 & 97.1 & 1.8 & 95.5 & 8.5 & 94.2 & 101.3 & 7.85 & 91.4 & 101 & 100.6 & 98.3 & 0.5 & 93.5 & 1.2 \\
\hline & 2 & 95.5 & 99.6 & 2.6 & 98.6 & 5.2 & 91.7 & 6.7 & 0.5 & 94.1 & 8 & 0.2 & 1.5 & 1.4 & 99.2 & 7.5 & 99.2 \\
\hline \multirow{2}{*}{ F12 } & 1 & 6 & 1 & 98.2 & 2.8 & 96.7 & 9.6 & 94.9 & 102.2 & 9 & 92.4 & 101.9 & 101.5 & 99.4 & 1.4 & 94.2 & 1.2 \\
\hline & 2 & 9 & 4 & 95.2 & 5.8 & 99.8 & 12.7 & 98.1 & 104 & 12.2 & 96 & 103.7 & 103.3 & 96.4 & 4.4 & 97.4 & 5.2 \\
\hline \multirow{3}{*}{ F13 } & 1 & 86.1 & 91.6 & 5 & 89.6 & 3.2 & 82.6 & 2 & 10 & 88.2 & 2.5 & 9.7 & 9.3 & 3.8 & 11.2 & 1.3 & 90.2 \\
\hline & 2 & 2.5 & 7.5 & 89.8 & 5.8 & 88.2 & 1.1 & 86.6 & 93.7 & 0.5 & 87.1 & 93.4 & 93 & 91 & 7.1 & 85.9 & 6.4 \\
\hline & 3 & 12 & 7 & 104.1 & 8.8 & 102.7 & 15.4 & 100.7 & 108.7 & 14.7 & 98.8 & 108.4 & 108 & 105.3 & 7.4 & 100 & 8.2 \\
\hline & 1 & 1.3 & 6.8 & 90.5 & 5.1 & 88.9 & 1.8 & 87.3 & 94.4 & 1.2 & 87.7 & 94.1 & 93.7 & 91.7 & 6.4 & 86.6 & 5.7 \\
\hline F14 & 2 & 95.1 & 84.6 & 5.2 & 101.2 & 7 & 93.8 & 8.7 & 4.1 & 94.2 & 7.6 & 3.8 & 3.4 & 4 & 84.2 & 8 & 101.8 \\
\hline & 3 & 11.5 & 6 & 103.6 & 7.8 & 102.2 & 14.9 & 100.2 & 108.3 & 14.3 & 98.3 & 108 & 107.6 & 104.8 & 6.4 & 99.5 & 7.2 \\
\hline & 1 & 2.8 & 2.2 & 95.1 & 0.5 & 93.6 & 6.5 & 91.9 & 99.1 & 6 & 89.4 & 98.8 & 98.4 & 96.3 & 1.8 & 91.2 & 1.1 \\
\hline F15 & 2 & 5.9 & 0.4 & 97.6 & 2.1 & 96.1 & 9 & 94.4 & 101.7 & 8.2 & 91.9 & 101.4 & 101 & 99.8 & 0.8 & 93.7 & 1.5 \\
\hline & 3 & 96.1 & 90.5 & 4 & 99.6 & 5.7 & 92.5 & 7.5 & 3.4 & 93 & 6.3 & 3.1 & 2.7 & 2.8 & 90.1 & 8.2 & 100.2 \\
\hline F16 & 1 & 11 & 5.7 & 103.3 & 7.2 & 101.8 & 14.5 & 99.9 & 107.8 & 13.9 & 98 & 107.5 & 107.1 & 104.5 & 6.1 & 99.2 & 6.6 \\
\hline 110 & 2 & 96.7 & 91.4 & 4.5 & 100.2 & 6.3 & 93.1 & 8.1 & 4 & 93.7 & 7 & 3.7 & 3.3 & 3.3 & 91 & 8.8 & 100.8 \\
\hline
\end{tabular}


Table 5. The distance $d_{i k, j l}$ between different possible locations of the facilities (b)

\begin{tabular}{|c|c|c|c|c|c|c|c|c|c|c|c|c|c|c|c|c|c|c|c|c|c|c|c|c|}
\hline No. & & F7 & & & F8 & & F9 & & & F10 & & F11 & & F12 & & F13 & & & F14 & & & F15 & & \\
\hline & $m$ & 1 & 2 & 3 & 1 & 2 & 1 & 2 & 3 & 1 & 2 & 1 & 2 & 1 & 2 & 1 & 2 & 3 & 1 & 2 & 3 & 1 & 2 & 3 \\
\hline \multirow{2}{*}{ F8 } & 1 & 95 & 98 & 2.1 & & & & & & & & & & & & & & & & & & & & \\
\hline & 2 & 92.3 & 100.8 & 30.6 & & & & & & & & & & & & & & & & & & & & \\
\hline \multirow{3}{*}{ F9 } & 1 & 91 & 96.6 & 2.9 & 3.8 & 1.3 & & & & & & & & & & & & & & & & & & \\
\hline & 2 & 4.4 & 1.6 & 96 & 21.4 & 96.4 & & & & & & & & & & & & & & & & & & \\
\hline & 3 & 7.3 & 2.2 & 102 & 96.4 & 100.4 & & & & & & & & & & & & & & & & & & \\
\hline \multirow{2}{*}{ F10 } & 1 & 95.7 & 101.1 & 2.3 & 0.6 & 2.9 & 4.7 & 99.7 & 102 & & & & & & & & & & & & & & & \\
\hline & 2 & 2.1 & 2.1 & 94.3 & 92.2 & 93.7 & 92.4 & 2.9 & 6.1 & & & & & & & & & & & & & & & \\
\hline \multirow{2}{*}{ F11 } & 1 & 93.8 & 99.2 & 0.9 & 6.3 & 1.5 & 2.5 & 97.5 & 100.1 & 6.8 & 0.7 & & & & & & & & & & & & & \\
\hline & 2 & 7.2 & 0.6 & 99.5 & 97 & 98.9 & 97.6 & 2.2 & 1.2 & 97.5 & 5.7 & & & & & & & & & & & & & \\
\hline \multirow{3}{*}{$\mathrm{F} 12$} & 1 & 94.5 & 100.2 & 0.9 & 0.5 & 2.5 & 3.1 & 98.6 & 101 & 1 & 96.2 & 3.40 & 92.90 & & & & & & & & & & & \\
\hline & 2 & 97.7 & 97.2 & 4.9 & 10.5 & 5.5 & 6.8 & 95.6 & 102.8 & 10 & 99.3 & 6.40 & 96.50 & & & & & & & & & & & \\
\hline & 1 & 1.6 & 4.6 & 90.5 & 87.6 & 80.9 & 9.7 & 5.4 & 8.8 & 88.1 & 3.7 & 90.20 & 3.00 & 87 & 90.2 & & & & & & & & & \\
\hline \multirow{3}{*}{ F13 } & 2 & 86.2 & 91.8 & 6.7 & 4 & 6.1 & 4.8 & 90.2 & 92.5 & 4.5 & 88.7 & 6.40 & 87.60 & 3.5 & 6.6 & & & & & & & & & \\
\hline & 3 & 100.2 & 2106.1 & 7.9 & 5.3 & 8.5 & 7.8 & 105.5 & 107.5 & 4.8 & 103.2 & 9.40 & 99.30 & 5.8 & 3 & & & & & & & & & \\
\hline & 1 & 86.2 & 92.5 & 6 & 2.8 & 5.4 & 4.1 & 90.9 & 93.2 & 3.3 & 89.4 & 5.70 & 88.20 & 2.3 & 5.4 & 84.4 & 0.8 & 8.1 & & & & & & \\
\hline \multirow{3}{*}{ F14 } & 2 & 7.7 & 3.2 & 102.1 & 96 & 101.5 & 100.2 & 4.8 & 2.9 & 97.1 & 7.5 & 101.80 & 8.10 & 96 & 99.2 & 11.2 & 92.6 & 101.9 & & & & & & \\
\hline & 3 & 99.8 & 105.6 & 6.9 & 4.8 & 7.5 & 9.2 & 104 & 107.1 & 4.3 & 102.7 & 8.40 & 98.80 & 5.3 & 2.5 & 97.5 & 14 & 0.5 & & & & & & \\
\hline & 1 & 91.5 & 96.9 & 1 & 4.3 & 0.8 & 0.5 & 95.5 & 97.9 & 4.8 & 94.1 & 1.10 & 89.90 & 3.8 & 6.9 & 89.1 & 5.3 & 9.6 & 4.5 & 100.1 & 99.1 & & & \\
\hline \multirow{3}{*}{ F15 } & 2 & 94 & 100.6 & 1.2 & 1 & 1.7 & 3 & 98 & 100.5 & 1.5 & 96.6 & 2.70 & 92.40 & 0.5 & 3.6 & 91.6 & 8.4 & 6.3 & 7.6 & 108.8 & 5.8 & & & \\
\hline & 3 & 7.9 & 2 & 100.5 & 97.6 & 99.9 & 98.6 & 3.6 & 2.2 & 98.1 & 6.2 & 100.20 & 6.80 & 97 & 100.2 & 9.9 & 93.6 & 102.9 & 94.4 & 5.2 & 102.4 & & & \\
\hline & 1 & 99.5 & 105.3 & 6.3 & 4.5 & 6.9 & 8.7 & 103.7 & 7106.6 & 4 & 102.3 & 7.80 & 98.50 & 5 & 2.1 & 97.1 & 13.5 & 0.8 & 12.7 & 108.5 & 50.3 & 8.8 & 5.5 & 103.2 \\
\hline F16 & 2 & 8.5 & 2.5 & 101.1 & 98.2 & 100.5 & 99.2 & 4.1 & 2.8 & 98.7 & 6.8 & 100.80 & 7.50 & 98 & 100.9 & 10.5 & 94.2 & 103.5 & 95 & 5.7 & 103 & 102.8 & 91.8 & 0.6 \\
\hline
\end{tabular}

Table 6. Sensitivity analysis for parameter selection of SA-based GA

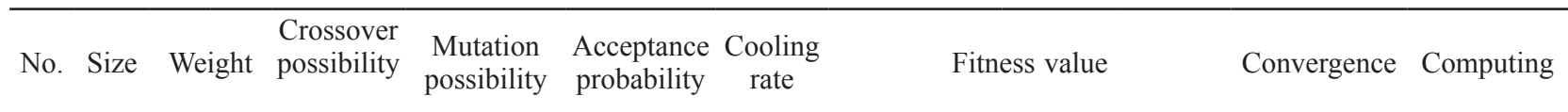

\begin{tabular}{|c|c|c|c|c|c|c|c|c|c|c|c|c|}
\hline & $\mathrm{N}$ & $k_{1}$ & $k_{2}$ & $p_{c}$ & $p_{m}$ & $P_{c}$ & $\rho$ & $f_{1}\left(10^{6}\right.$ yuan $)$ & $f_{2}$ & $f$ & $\begin{array}{l}\text { Iteration } \\
\text { number }\end{array}$ & Times (s) \\
\hline 1 & 30 & 1.2 & 1.2 & 0.7 & 0.05 & 0.95 & 0.95 & 35,627 & 674270 & 3646.20 & 2 & 61.969 \\
\hline 2 & 30 & 1.2 & 1.2 & 0.8 & 0.05 & 0.95 & 0.95 & 33,481 & 422060 & 3928.00 & 1 & 57.219 \\
\hline 3 & 30 & 1.2 & 1.2 & 0.7 & 0.2 & 0.95 & 0.95 & 24,803 & 728700 & 3240.00 & 1 & 60.187 \\
\hline 4 & 30 & 1.2 & 1.2 & 0.7 & 0.05 & 0.9 & 0.95 & 36,871 & 886170 & 3210.47 & 3 & 50.468 \\
\hline 5 & 30 & 1.2 & 1.2 & 0.7 & 0.05 & 0.95 & 0.9 & 32,948 & 836030 & 3240.00 & 2 & 60.391 \\
\hline 6 & 50 & 1.2 & 1.2 & 0.7 & 0.05 & 0.95 & 0.95 & 51,253 & 616670 & 5271.33 & 2 & 107.812 \\
\hline 7 & 50 & 1.2 & 1.2 & 0.8 & 0.05 & 0.95 & 0.95 & 63,327 & 289080 & 7756.68 & 3 & 106.391 \\
\hline 8 & 50 & 1.2 & 1.2 & 0.7 & 0.2 & 0.95 & 0.95 & 62,660 & 698950 & 9000.12 & 3 & 106.922 \\
\hline 9 & 50 & 1.2 & 1.2 & 0.7 & 0.05 & 0.9 & 0.95 & 64,673 & 686150 & 9026.89 & 4 & 104.188 \\
\hline 10 & 50 & 1.2 & 1.2 & 0.7 & 0.05 & 0.95 & 0.9 & 34,506 & 687120 & 5677.23 & 5 & 108.234 \\
\hline 11 & 30 & 1.8 & 1.2 & 0.7 & 0.05 & 0.95 & 0.95 & 39,171 & 791702 & 7972.00 & 2 & 65.562 \\
\hline 12 & 30 & 1.8 & 1.2 & 0.8 & 0.05 & 0.95 & 0.95 & 29,347 & 726610 & 9614.00 & 3 & 65.329 \\
\hline 13 & 30 & 1.8 & 1.2 & 0.7 & 0.2 & 0.95 & 0.95 & 29,145 & 855620 & 8488.00 & 1 & 66.328 \\
\hline 14 & 30 & 1.8 & 1.2 & 0.7 & 0.05 & 0.9 & 0.95 & 36,120 & 843920 & 7469.00 & 2 & 66.484 \\
\hline 15 & 30 & 1.8 & 1.2 & 0.7 & 0.05 & 0.95 & 0.9 & 37,222 & 824750 & 5973.00 & 2 & 66.156 \\
\hline 16 & 30 & 1.2 & 1.8 & 0.7 & 0.05 & 0.95 & 0.95 & 58,217 & 724780 & 8030.00 & 3 & 66.453 \\
\hline 17 & 30 & 1.2 & 1.8 & 0.8 & 0.05 & 0.95 & 0.95 & 59,956 & 529410 & 9157.00 & 1 & 66.641 \\
\hline 18 & 30 & 1.2 & 1.8 & 0.7 & 0.2 & 0.95 & 0.95 & 53,294 & 518360 & 8210.00 & 2 & 66.265 \\
\hline 19 & 30 & 1.2 & 1.8 & 0.7 & 0.05 & 0.9 & 0.95 & 56,508 & 746080 & 5043.00 & 1 & 66.062 \\
\hline 20 & 30 & 1.2 & 1.8 & 0.7 & 0.05 & 0.95 & 0.9 & 50,908 & 704590 & 5207.00 & 4 & 64.922 \\
\hline
\end{tabular}


preliminary experiments that were conducted to observe the behavior of the algorithm at different parameter settings. To reduce potential statistical errors, the convergence iteration number and computing time of the algorithm was also calculated. By comparing several sets of parameters, the most reasonable parameters were chosen: $N=100, p_{c}=0.8, p_{m}=0.2, P_{c}=0.95$ and $\rho=0.95$. We ran the DDTFLPP program 30 times and chose the best result as our solution for which the first objective was 72,422 million yuan and the second was 706,654 . The total fitness value was 7574.8. The detailed information is shown in Figure 6. We can see some of the facilities were relocated at each stage, while some had no change over several stages. This difference is not only related to the cost balance for the DDTFLPP program model but can also be explained from the practical experience.

We may get different results from different runs of the program. The project management can select the most suitable solution by considering the real environment, such as the local residents, the transportation condition and the safety. Hydropower stations are often located in mountainous area with a severe environment. So, some candidates that may have economic advantages may not be very safe because of the possibility of debris flow, or flood or the other events caused by the environment and the weather. The selection process can also be influenced by the local government policy. Therefore, decision makers need to consider the conditions comprehensively before making a final decision.

In order to gain insight into parameter selection, a sensitivity analysis was conducted as shown in Table 6. Decision makers can fine tune these parameters to obtain different solutions. Under the same level as the other parameters, the average computing time for the population size $N=50$ was about 1.65 times that of $N=30$ and indicated that we can obtain better results with a larger population size. When the crossover probability $p_{c}=50$ and the mutation probability $p_{m}$ increased respectively, the results were better. Further the effect of $p_{c}$ was greater than the $p_{m}$. The cooling rate $\rho$ and the probability of acceptance had little effect on the results.

In addition, the weight $k$ in the evaluation value $F$ used to find the optimal feasible solution was chosen randomly. As a result, it was a significant factor in the fluctuation of $F$. For each pair of $k_{1}$ and $k_{2}$, we still ran the program 30 times and chose the best fitness as the results. To show the practicality and efficiency of the optimization method, the results are discussed in Table 6. In practice, $k$ reflects the different attitudes of the objectives and can be set according to the preference of the decision maker.

The proposed methodology provided a systematic approach to narrow down the number of alternatives, and to facilitate the decision making process. These results are quite useful and could be used as reference for the decision-makers as, ultimately, they will be the ones who will make the choice of the appropriate set of parameters to optimize the decision making process. For this propose then, the DDTFLPP model for the development of the actual material use profiles for the construction activities presented in this paper is simple and practical.

An on-going extension of this proposed approach is the comprehensive testing of its efficiency on a range of different construction sites to quantify its impact. This is, however, a difficult and long-term task that requires a large number of projects and the analysis of various site productivity measurement statistics.

\subsection{Model comparison}

In the past, the DDTFLPP was modeled with a surrogate function for flow distance or for simplified objectives that may be entrapped into the local optimum, such as in Urban's (1998) model, where the material flow was considered but the other factors were not. To find out how well each modeling method contributed to the DDTFLPP, every objective was respectively considered. Rosenblatt's (1986) model was used to solve the DDTFLPP problem for the Jinping-II hydropower station using the same given parameters. The objective was only $f_{1}$ for this model and the result was 12,330 million yuan, 60,090 million yuan less than 72,442 million yuan, the result of our multi-objectives model. While the second objective $f_{2}$ was 839,583 at the same time, 132,929 higher (18.81\%) than 706,654 , the result of the multi-objectives model. Similarly, if $f_{2}$ is used as the only objective, the result was $46,122,660,532$ less than the model while the cost $\left(f_{1}\right)$ was 79,189 million yuan, 6,767 million yuan $(9.34 \%)$ higher. Thus, the multi-objective integration method used in the model here has a greater effect on the outcomes. Furthermore, this model is more suitable for construction as the project manager needs to consider both the cost and the relationship at the same time.

\begin{tabular}{|c|c|c|c|c|c|c|c|c|c|c|c|c|c|c|c|c|}
\hline $\begin{array}{c}\text { Temponary } \\
\text { facilities } \\
\text { items }\end{array}$ & $\begin{array}{l}\text { Concrete } \\
\text { system }\end{array}$ & $\begin{array}{c}M E C \\
\text { installation }\end{array}$ & $\begin{array}{l}\text { Fabrication } \\
\text { plant } \\
\text { synthesis }\end{array}$ & $\begin{array}{c}\text { Steel } \\
\text { fabrication } \\
\text { yard }\end{array}$ & $\begin{array}{c}\text { Sandstone } \\
\text { fabrication } \\
\text { plant }\end{array}$ & $\begin{array}{l}\text { Maintenance } \\
\text { shop }\end{array}$ & $\begin{array}{l}\text { Carpentry } \\
\text { shop }\end{array}$ & $\begin{array}{l}\text { Storage } \\
\text { plant }\end{array}$ & $\begin{array}{c}\text { Cement/Sand// } \\
\text { Aggregate } \\
\text { storage yard }\end{array}$ & $\begin{array}{l}\text { Machine } \\
\text { room }\end{array}$ & $\begin{array}{c}\text { Explosive } \\
\text { depot }\end{array}$ & $\begin{array}{l}\text { Oil } \\
\text { depot }\end{array}$ & $\begin{array}{l}\text { Utility } \\
\text { area }\end{array}$ & $\begin{array}{l}\text { Office } \\
\text { area }\end{array}$ & $\begin{array}{c}\text { Parking } \\
\text { lot }\end{array}$ & $\begin{array}{c}\text { Refuse } \\
\text { dumping } \\
\text { area }\end{array}$ \\
\hline \multirow[t]{2}{*}{ Stage 1 } & F1-2 & F2-1 & F3-1 & F4-1 & F5-3 & F6-2 & F7-3 & F8-1 & F9-1 & F10-1 & F11-1 & F12-1 & F13-2 & F14-1 & F15-1 & F16-1 \\
\hline & $\downarrow$ & $\downarrow$ & $\downarrow$ & $\downarrow$ & $\downarrow$ & $\downarrow$ & $\downarrow$ & $\downarrow$ & $\downarrow$ & $\downarrow$ & $\downarrow$ & $\downarrow$ & $\downarrow$ & $\downarrow$ & $I$ & $\downarrow$ \\
\hline \multirow[t]{3}{*}{ Stage 2} & F1-2 & F2-2 & F3-2 & F4-2 & F5-2 & F6-1 & F7-1 & F8-2 & F9-2 & F10-2 & F11-2 & $\mathrm{F} 12-2$ & F13-3 & F14-3 & $\mathrm{F} 15-2$ & F16-3 \\
\hline & $\downarrow$ & $\downarrow$ & $\downarrow$ & $i$ & $\downarrow$ & $\downarrow$ & $\downarrow$ & $\downarrow$ & $\downarrow$ & $\downarrow$ & $\downarrow$ & $\downarrow$ & $\downarrow$ & $\downarrow$ & $\downarrow$ & $\downarrow$ \\
\hline & F1-3 & F2-2 & F3-2 & $F 4-2$ & F5-2 & F6-1 & F7-1 & F8-2 & F9-2 & F10-2 & F11-2 & F12-2 & F13-1 & F14-2 & F15-3 & $\mathrm{F} 16-3$ \\
\hline
\end{tabular}

Fig. 6. Dynamic allocation plan for the DDTFLPP of the Jinping-II hydropower station 
Many existing research papers have tackled the DDTFLPP process in chronological order (Zouein, Tommelein 1999). According to Osman et al. (2003), this approach has its drawbacks and the main weakness lies in the fact that facilities that are assigned positions in early phases may:

(1) Be placed in positions that will subsequently be occupied by permanent facilities, thus they will be forced to relocate.

(2) Be placed in positions that minimize the transportation costs during early phases but in subsequent phases might be in unfavorable as they are far from other facilities.

In contrast, our paper proposes a model that mitigates the costs of the DDTFLPP for all phases combined. However, this model is not suited to a layout problem with only a few facilities in a small area, such as the Khaled's dynamic site layout planning problem (Haidar et al. 2009) because neither the orientation of the facilities nor geometric constraints are considered.

\subsection{Algorithm evolution}

To compare the performance of the algorithms, we also solved the DDTFLPP program using the MOGA. For each type, we ran the DDTFLPP program 10 times with the same value for the parameters. The searching process of the SA-based MOGA can be seen in Figure 7. The results and performance of the algorithm and the actual data from the project are listed in Table 7. The fitness value for the SA-based MOGA is better than for the MOGA. This shows that the SA-based MOGA has a better ability to aggregate the different objectives. This improvement demonstrates that the SA-based MOGA is more suitable for the DDTFLPP proposed in this study. However, the SA-based MOGA shows very limited updating in the convergence as the iteration number is around 2. This is because the variables are $0-1$ and the number of variables is small, so the search process is short. When the number of the variables increases, the SA-based GA shows greater advantage.

As shown in Table 7, the best, the worst, and the average results for the different algorithms were also stated. It is worth noting that the gap between the best and the worst solutions for SA-based MOGA is narrower than those for the MOGA. This is the same for the gap between the best and the average solution. This shows that SA-based MOGA creates a more stable solution space. This point also suggests the SA-based MOGA is an effective and relatively efficient approach for solving the DDTFLPP.

\subsection{Effectiveness analysis}

Table 7 shows that there are significant differences between the proposed methodology and the actual outcomes. Project managers are interested in these differences because this knowledge would give them further insight for future practical cases. For the SA-based MOGA, the rate of increase of the first objective between the result and the actual data is $6.2 \%$. Such an improvement assists in reducing costs for the construction project. Further, the

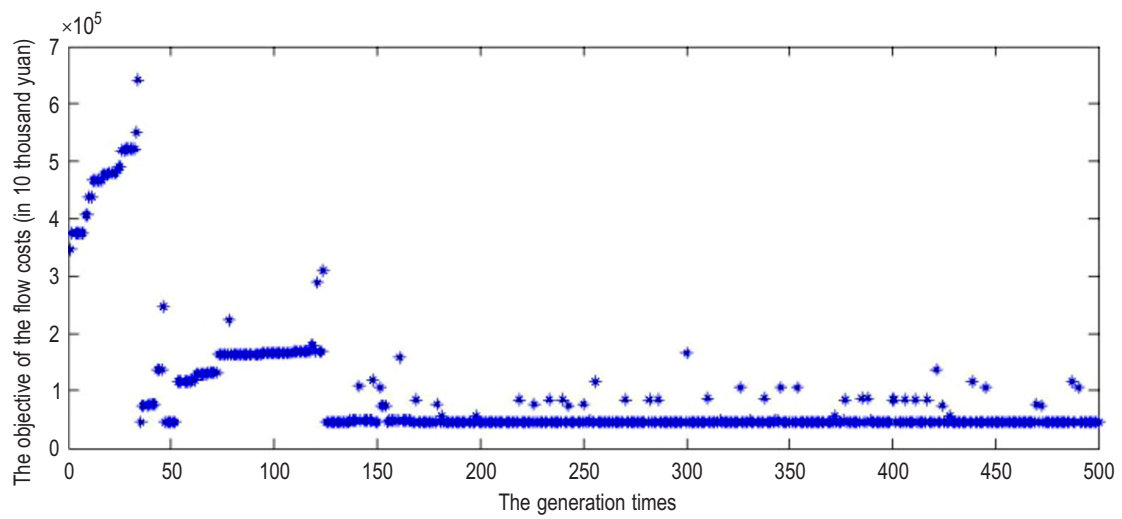

Fig. 7. The searching process of SA-based MOGA

Table 7. The comparison of the algorithms

\begin{tabular}{|c|c|c|c|c|c|c|c|c|c|c|c|c|c|c|}
\hline \multirow[t]{3}{*}{ Algorithm } & \multirow{3}{*}{$\begin{array}{c}\text { Stage } \\
t\end{array}$} & \multicolumn{4}{|c|}{ Cost (in million yuan) } & \multicolumn{3}{|c|}{ Data $=795470$} & \multicolumn{3}{|c|}{ Fitness } & \multirow[t]{2}{*}{ Variance } & \multirow[t]{2}{*}{ Convergence } & \multirow[t]{2}{*}{ Time } \\
\hline & & & & $f_{1}$ & & & $f_{2}$ & & & $f$ & & & & \\
\hline & & Result & Data & Increase & Rate & Result & Increase & Rate & Best & Worst & Average & & $\begin{array}{c}\text { iteration } \\
\text { number }\end{array}$ & \\
\hline \multirow[t]{4}{*}{$\begin{array}{c}\text { SA-based } \\
\text { MOGA }\end{array}$} & 1 & 31,568 & 32,574 & 1,006 & $3.09 \%$ & \multirow{3}{*}{706654} & \multirow{3}{*}{88816} & \multirow{3}{*}{$11.17 \%$} & \multirow{3}{*}{7554} & \multirow{3}{*}{7532} & \multirow{3}{*}{7500} & \multirow{3}{*}{$22.0589 \%$} & 1 & 67.893 \\
\hline & 2 & 62,838 & 66,556 & 3,718 & $5.59 \%$ & & & & & & & & & \\
\hline & 3 & 72,422 & 77,208 & 4,786 & $6.20 \%$ & & & & & & & & & \\
\hline & 1 & 26,653 & 32,574 & 5,921 & $18.18 \%$ & \multirow{3}{*}{718261} & \multirow{3}{*}{77209} & \multirow{3}{*}{$9.71 \%$} & \multirow{3}{*}{6092} & \multirow{3}{*}{5945} & \multirow{3}{*}{6076} & \multirow{3}{*}{$28.9943 \%$} & \multirow{3}{*}{5} & \multirow{3}{*}{7.047} \\
\hline \multirow[t]{2}{*}{ MOGA } & 2 & 43,392 & 66,556 & 23,164 & $34.80 \%$ & & & & & & & & & \\
\hline & 3 & 58,793 & 77,208 & 18,415 & $23.85 \%$ & & & & & & & & & \\
\hline
\end{tabular}


closeness relationships between the facilities are able to attain a suitable level of which the net rate of increase is $11.17 \%$. Consequently, the construction project safety level can be also improved.

Although these finding are quite encouraging, for now, it is not $100 \%$ certain that all these differences represent a net improvement because our mathematical model is formulated on some assumptions. Some portion of these differences could be a result of possible modeling errors. In fact, as the basis for future decisions on the DDTFLPP, the hydropower station managers have already adopted the analysis results.

\section{Conclusions}

Ultimately, from the above statement, we can conclude that this paper has presented a new hybrid optimization model for the DDTFLPP of the large scale hydropower station by combining traditional research theory, practitioners' perceptions and a mathematical approach. The traditional model has been improved to develop a more suitable model making it easier to apply for project managers. The results show that the proposed method is viable for the DDTFLPP. The methods and experiences learned from this study are valuable for the future strategic management planning for large scale hydropower stations. More specifically, this model may significantly enhance a project managers' DDTFLPP comprehension and the management of the large project cases. Therefore, the study is applicable and useful to the profession.

Cost and safety concerns are the key factors for a productive construction site. In this paper, the factors that contribute to inefficiency were discussed and the need for uncertainty to be integrated into site layout planning emphasized. Four aspects were considered for the DDTFLPP:

(1) defining the facilities closeness weights based on a modification of the defuzzification methodology;

(2) proposing a multi-objective dynamic construction layout planning model under a fuzzy uncertainty environment;

(3) developing an SA-based GA to find feasible solutions;

(4) presenting a practical study to demonstrate the applicability and significant benefits of the proposed approach.

In addition, there were only 3 stages in our case study. When a problem includes numerous stages, data entry for each can become tedious. It is possible to build a database of typical resource dimensions, constraints, and weights, so as to alleviate this task.

On the other hand, there are other investigation methods and algorithms worth pursuing for the DDTFLPP. The proposed model is based on a critical assumption of treating the facilities as dots, which is generally only appropriate for large scale hydropower construction projects. Consequently, this leads to a limited application as most other projects do not have large areas as in a large scale hydropower construction projects. In those conditions, every facility has to occupy some area so they cannot be treated as discrete dots, so our model would not perform well. Further, there are some other objectives in the DDTFLPP, such as environmental pollution and construction delay which have not been considered here. These would become possible future research opportunities to assist project managers gain deeper insight into the management of this classical yet important research area and ensure successful project implementation.

\section{Acknowledgements}

The authors would like to thank the editors and anonymous referees for their useful comments and suggestions, which helped to improve this paper. This research is supported by the Key Program of National Natural Science Foundation of China (Grant No. 70831005), and also supported by "985" Program of Sichuan University "Innovative Research Base for Economic Development and Management".

\section{References}

Aiello, G.; Enea, M.; Galante, G. 2006. A multi-objective approach to facility layout problem by genetic search algorithm and Electre method, Robotics and Computer-Integrated Manufacturing 22: 447-455. http://dx.doi.org/10.1016/j.rcim.2005.11.002

Back, T.; Fogel, D.; Michalewicz, Z. 2000. Handbook of evolutionary computation. Bristol: IOP Publishing Ltd., Oxford University Press.

Baykasoglu, A.; Dereli, T.; Sabuncu, I. 2006. An ant colony algorithm for solving budget constrained and unconstrained dynamic facility layout problems, Omega 34: 385-396. http://dx.doi.org/10.1016/j.omega.2004.12.001

Bennage, W. A.; Dhingra, A. K. 1995. Single and multi-objective structural optimization in discrete-continuous variables using simulated annealing, International Journal for Numerical Methods in Engineering 38: 2753-53. http://dx.doi.org/10.1002/nme.1620381606

Cheung, S.; Tong, T.; Tam, C. 2002. Site pre-cast yard layout arrangement through genetic algorithms, Automation in Construction 11(1): 35-46. http://dx.doi.org/10.1016/S0926-5805(01)00044-9

Deb, S. K.; Bhattacharyya, B. 2005. Fuzzy decision support system for manufacturing facilities layout planning, Decision Support Systems 40: 305-314. http://dx.doi.org/10.1016/j.dss.2003.12.007

Domschke, W.; Krispin, G. 1997. Location and layout planning - a survey, Operations-Research-Spektrum 19: 181194. http://dx.doi.org/10.1007/BF01545586

Dweiri, F.; Meier, F. A. 1996. Application of fuzzy decisionmaking in facilities layout planning, International Journal of Production Research 34(11): 3207-3225. http://dx.doi.org/10.1080/00207549608905085

El-Rayes, K.; Said, H. 2010. Dynamic site layout planning using approximate dynamic programming, Journal of Computing in Civil Engineering 23(2): 119-127.

http://dx.doi.org/10.1061/(ASCE)0887-3801(2009)23:2(119)

Elbeltagi, E.; Hegazy, T. 2001. A hybrid AI-based system for site layout planning in construction site, Computer-Aided Civil and Infrastructure Engineering 16(2): 79-93. http://dx.doi.org/10.1111/0885-9507.00215 
Elbeltagi, E.; Hegazy, T.; Hosny, A.; Eldosouky, A. 2001. Schedule-dependent evolution of site layout planning, Construction Management and Economics 19(7): 689697. http://dx.doi.org/10.1080/01446190110066713

Elbeltagi, E.; Hegazy, T. 2004. Dynamic layout of construction temporary facilities considering safety, Journal of Construction Engineering and Management 130(4): 534-541.

http://dx.doi.org/10.1061/(ASCE)0733-9364(2004)130:4(534)

Emre, G.; Gürcanli, G.; Muüngen, U. 2009. An occupational safety risk analysis method at construction sites using fuzzy sets, International Journal of Industrial Ergonomics 39: 371-387.

http://dx.doi.org/10.1016/j.ergon.2008.10.006

Fortenberry, J.; Cox, J. 1985. Multiple criteria approach to the facilities layout problem, International Journal of Production Research 23(4): 773-782. http://dx.doi.org/10.1080/00207548508904746

Goldberg, D. E. 1989. Generatic algorithms in searching optimization and machine learning. Reading, Massachusetts: Addision Wesley.

Gentile, M.; Rogers, W. J.; Mannan, M. S. 2003. Development of an inherent safety index based on fuzzy logic, AIChE Journal 49(4): 959-968. http://dx.doi.org/10.1002/aic.690490413

Gang, J.; Xu, J. 2010. The resource-constraint project scheduling with multi-mode under fuzzy random environment in the drainage engineering of LT hydropower, International Journal of Logistics and Transportation 4(2): 53-80.

Gangolells, M.; Casals, M.; Forcada, N.; Roca, X.; Fuertes, A. 2010. Mitigating construction safety risks using prevention through design, Journal of Safety Research 41: 107122. http://dx.doi.org/10.1016/j.jsr.2009.10.007

Haidar, A.; Naoum, S.; Howes, R.; Tah, J. 2009. Genetic algorithms application and testing for equipment selection, Journal of Construction Engineering and Management 125(1): 32-38.

http://dx.doi.org/10.1061/(ASCE)0733-9364(1999)125:1(32)

Kirkpatrick, S.; Gelatt, Jr. C. D.; Vecchi, M. P. 1983. Optimisation by simulated annealing, Science 220: 671-680. http://dx.doi.org/10.1126/science.220.4598.671

Karray, F.; Zaneldin, E.; Hegazy, T.; Shabeeb, A. H. M.; Elbeltagi, E. 2000. Tools of soft computing as applied to the problem of facilities layout planning, IEEE Transactions on Fuzzy Systems 8(4): 367-379. http://dx.doi.org/10.1109/91.868944

Li, H.; Love, P. 1998. Site-lever facilities layout using genetic algorithms, Journal of Computing in Civil Engineering 12(4): 227-231.

http://dx.doi.org/10.1061/(ASCE)0887-3801(1998)12:4(227)

Maravas, A.; Pantouvakis, J. 2012. Project cash flow analysis in the presence of uncertainty in activity duration and cost, International Journal of Project Management 30: 374384. http://dx.doi.org/10.1016/j.ijproman.2011.08.005

Mawdesley, M. J.; Al-Jibouri, S. H. 2003. Proposed genetic algorithms for construction site layout, Engineering Applications of Artificial Intelligence 16: 501-509. http://dx.doi.org/10.1016/j.engappai.2003.09.002

Meller, R.; Gau, K. 1996. The facility layout problem: recent and emerging trends and perspectives, Journal of Manufacturing Systems 15(5): 351-366. http://dx.doi.org/10.1016/0278-6125(96)84198-7

Nicklow, J.; Reed, P.; Savic, D.; Dessalegne, T.; Harrell, L.; Chan-Hilton, A.; Karamouz, M.; Minsker, B.; Ostfeld, A.; Singh, A. 2010. State of the art for genetic algorithms and beyond in water resources planning and management, Journal of Water Resources Planning and Management 136(4): 412-432.

http://dx.doi.org/10.1061/(ASCE)WR.1943-5452.0000053

Ning, X.; Lam, K. C.; Lam, M. C. 2010. Dynamic construction site layout planning using max-min ant system, Automation in Construction 19(1): 55-65.

http://dx.doi.org/10.1016/j.autcon.2009.09.002

Ning, X.; Wang, L. G. 2011. Construction site layout evaluation by intuitionistic fuzzy TOPSIS model, Applied Mechanics and Materials 71: 583-588.

http://dx.doi.org/10.4028/www.scientific.net/AMM.71-78.583

Rosenblatt, M. 1986. The dynamics of plant layout, Management Science 32(1): 76-86. http://dx.doi.org/10.1287/mnsc.32.1.76

Saaty, T. L. 1980. The analytical hierarchy process. New York: McGraw-Hill.

Soltani, A. R.; Fernando, T. 2004. A fuzzy based multi-objective path planning of construction sites, Automation in Construction 13(6): 717-734.

http://dx.doi.org/10.1016/j.autcon.2004.04.012

Tompkins, J. A.; White, J. A.; Bozer, Y. A.; Frazelle, E. H.; Tanchoco, J. M.; Trevino, J. 1996. Facilities planning. New York: Wiley.

Turskis, Z.; Zavadskas, E. K.; Peldschus, F. 2009. Multi-criteria optimization system for decision making in construction design and management, Inzinerine Ekonomika - Engineering Economics 61(1): 7-17.

Osman, H. M.; Georgy, M. E.; Ibrahim, M. E. 2003. An automated system for dynamic construction site layout planning, in Tenth International Colloquium on Structural and Geotechnical Engineering, 22-24 April 2003, Ain Shams University, Cairo, Egypt.

Urban, T. L. 1998. Solution procedures for the dynamic facility layout problem, Annals of Operations Research 76: 323-342. http://dx.doi.org/10.1023/A:1018904806854

$\mathrm{Xu}$, J.; Zhou, Y. 2010. Fuzzy-like multiple objective decision making. New York: Springer-Verlag.

Xu, J.; Li, M. 2012. Multi-objective dynamic construction site layout planning under fuzzy random environment, Automation in Construction 27: 155-169. http://dx.doi.org/10.1016/j.autcon.2012.05.017

$\mathrm{Xu}$, J.; Zhang, Z. 2012. A fuzzy random resource-constrained scheduling model with multiple projects and its application to a working procedure in a large-scale water conservancy and hydropower construction project, Journal of Scheduling 15(2): 253-272. http://dx.doi.org/10.1007/s10951-010-0173-1

Yang, T.; Hung, C. C. 2007. Multiple-attribute decision making methods for plant layout design problem, Robotics and Computer-Integrated Manufacturing 23: 126-137. http://dx.doi.org/10.1016/j.rcim.2005.12.002

Yeh, I. 1995. Construction-site layout using annealed neural network, Journal of Computing in Civil Engineering 9(3): 201-208. http://dx.doi.org/10.1061/(ASCE)0887-3801(1995)9:3(201)

Zadeh, L. A. 1965. Fuzzy sets, Information and Control 8: 338553. http://dx.doi.org/10.1016/S0019-9958(65)90241-X

Zétényi, T. 1988. Fuzzy sets in psychology. North Holland: Elsevier.

Zouein, P.; Tommelein, I. 1999. Dynamic layout planning using a hybrid incremental solution method, Journal of Construction Engineering and Management 125(6): 400-408.

http://dx.doi.org/10.1061/(ASCE)0733-9364(1999)125:6(400) 
Jiuping XU. He obtained his $\mathrm{PhD}$ in applied mathematics from Tsinghua University, and $\mathrm{PhD}$ in physical chemistry from Sichuan University, in 1995 and 1999, respectively. Dr. Xu is a Distinguished Prof. of the "Chang Jiang Scholars Program" of the Ministry of Education of the P. R. China, the Dean of the Business School of Sichuan University. Prof. Xu was appointed a lifetime academician of the International Academy of Systems and Cybernetic Sciences in 2010. He is the President of the International Society for Management Science and Engineering Management, and the Vice-President of The Systems Engineering Society of China, Vice-President of the Chinese Society of Optimization \& Overall Planning and Economical Mathematics, the Editor in Chief of The International Journal of Management Science and Engineering Management. He has published more than 50 official books and 400 journal papers.

Qiurui LIU. She is a PhD candidate of Management Science and Engineering. Sichuan University, P. R. China. She is an editor of World Journal of Modeling and Simulation. Her interests include supply management optimization, construction engineering and management, scheduling and operations management.

Xiao LEI. He got his PhD of Power System Automation from Wuhan University, P. R. China. He is a Senior Engineer and the Contract Management Deputy Director of China Three Gorges Corporation. His research interests include contract management optimization and contract post-evaluations. 